Portland State University

PDXScholar

3-12-2021

\title{
Returning to Rejection: Outcomes and Boundary Conditions of Mental Illness Stereotypes
}

Stefanie Fox

Portland State University

Follow this and additional works at: https://pdxscholar.library.pdx.edu/open_access_etds

Part of the Mental and Social Health Commons, and the Psychology Commons Let us know how access to this document benefits you.

\section{Recommended Citation}

Fox, Stefanie, "Returning to Rejection: Outcomes and Boundary Conditions of Mental Illness Stereotypes" (2021). Dissertations and Theses. Paper 5671.

https://doi.org/10.15760/etd.7543

This Thesis is brought to you for free and open access. It has been accepted for inclusion in Dissertations and Theses by an authorized administrator of PDXScholar. Please contact us if we can make this document more accessible: pdxscholar@pdx.edu. 


\section{Returning to Rejection:}

Outcomes and Boundary Conditions of Mental Illness Stereotypes

by

Stefanie Fox

A thesis submitted in partial fulfillment of the requirements for the degree of

Master of Science

in

Psychology

Thesis Committee:

Liu-Qin Yang, Chair

Larry Martinez

Jason Newsom

Portland State University

2021 
(C) 2021 Stefanie Fox 


\begin{abstract}
Mental illness is a common condition in the United States, with over $20 \%$ of working age adults managing a mental illness condition in a given year. Disclosure of mental illness is often required for workers to take advantage of employer-provided resources (e.g., accommodations), yet use of resources is exceedingly low (less than $10 \%$ ). Negative stigma-related outcomes are a top reason for which individuals delay the use of resources. Using an experimental design in an online data collection of 242 participants over two time points, the current study builds on existing organizational diversity literature to examine the stereotypes associated with mental illness. Drawing from the Stereotype Content Model (SCM), Behaviors from Intergroup Affect and Stereotypes Map (BIAS map), and Gender Role Theory, I explore competence and warmth stereotypes as predictors of differentiated negative interpersonal workplace outcomes, and examine gender as a potential boundary condition of the relations between mental illness status, stereotype perceptions and interpersonal outcomes. Results suggest that for the current study, though hypothesized relationships were not supported, mental illness status was related to a reduced desire of participants to work with individuals managing mental illness. Additionally, competence and warmth perceptions demonstrated differential prediction of both inclusive and exclusive interpersonal intentions, extending understandings on the applicability of the SCM and BIAS map to the workplace.
\end{abstract}


Table of Contents

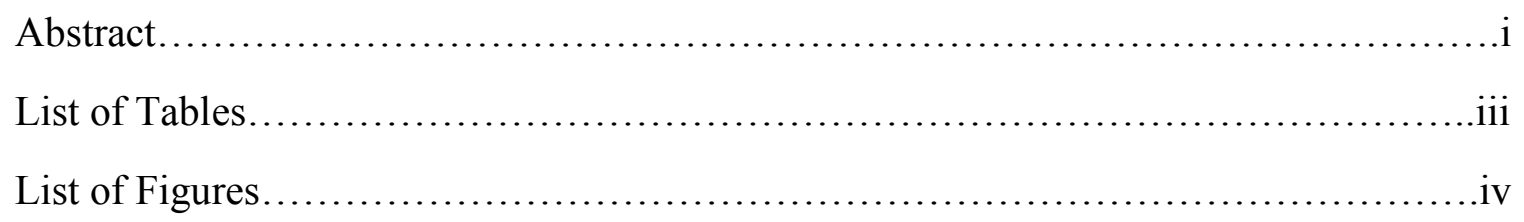

Chapter 1: Introduction...................................................

Chapter 2: Hypothesis Development............................................

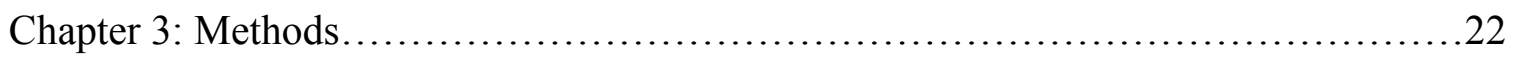

Chapter 4: Results......................................................29

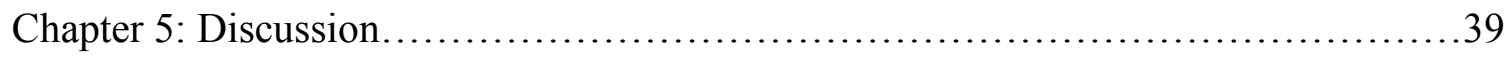

Tables............................................................... 52

Figures............................................................... 58

References...........................................................59

Appendix A: Data Collection Measures.......................................69

Appendix B: Stimulus Materials............................................ 73 


\section{List of Tables}

Table 1: Logistic Regression and Chi-square Attrition Analyses.......................52

Table 2: Means, Standard Deviations, Correlations, and Reliability of Focal

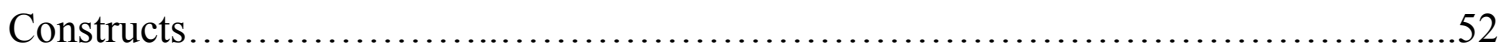

Table 3: Results of Confirmatory Factor Analysis of Focal Constructs..................53

Table 4: Results of Nested Confirmatory Factor Analysis of Hypothesized

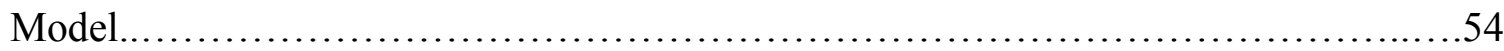

Table 5: Mean and Standard Deviation of Focal Mediators and Outcomes

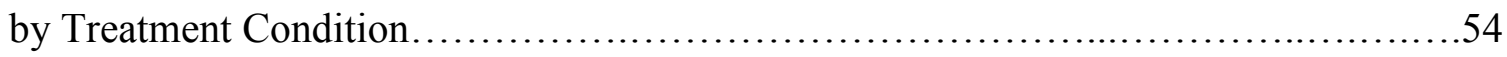

Table 6: Model Estimates for Indirect Effects...................................55

Table 7: Results of Moderation of Mental Illness on Focal Mediators...................56

Table 8: Model Estimates for Conditional Indirect Effects............................57 


\section{List of Figures}

Figure 1: Hypothesized Conceptual Model.....................................58 


\section{Chapter 1: Introduction}

In 2016 , over $20 \%$ of working age adults in the United States (i.e., 18-49 years old) experienced a mental illness, and according to the National Institute of Mental Health (2016) women were 1.5 times more likely than men to experience mental illness. Furthermore, nearly one third of employed workers have reported managing mental illness at least once in their career (Ipsos, 2012). Mental illness includes mental, behavioral, and emotional disorders and can vary in impairment from non-impairing to mild, moderate, or severely impairing (National Institute of Mental Health, 2016). These impairments can impact every area of an affected individual's life, including home life, personal relationships, and work opportunities and relationships. Though treatment is widely available, only $43 \%$ of American adults with a diagnosed mental illness seek treatment within a given year (NIMH, 2016) .

In addition to personal impairment caused by a mental illness, an individual's personal and professional work functioning can be impaired by the attitudes and behaviors directed toward them from supervisors and coworkers. Workers with mental illness often experience negative attitudes and discriminatory behaviors from others, signaling a stigmatized identity (Follmer \& Jones, 2018). A stigmatized identity is heralded by discrediting attributes that indicate a devalued stereotype (Goffman, 1963). These stereotypes are one of the top reasons for the low rate of disclosure and resource use for workers with mental illness, further compounding the workplace challenges they face (Dimoff \& Kelloway, 2016; Follmer \& Jones, 2018). The purpose of this experimental study is to examine stereotypes for workers with mental illness, demonstrate that stereotypes for these workers lead to negative interpersonal outcomes, 
and explore how a worker's gender accounts for differential effects of their mental illness status on the stereotypes they experience and associated work outcomes.

Stereotypes associated with individuals managing mental illness are reflected in lowered perceptions of competence and warmth (Fiske et al., 2002). These stereotypes result from the perception that individuals with mental illness have increased potential for unpredictable behavior that interferes with attaining group goals along with reduced ability to achieve their personal goals (Becker \& Asbrock, 2012; Fiske et al., 2002). Stereotypes lead to prejudice (i.e., affective reactions) and can manifest as discriminatory behaviors. When the individual being evaluated is not both well-liked and respected, the resulting stereotypes are often negative or ambivalent (i.e., containing both negative and positive dimensions).

Thus far, workplace mental illness stigma literature has examined competence and warmth stereotypes of generally labeled mental illness and of specific mental illnesses (e.g., depression, anxiety; see Sadler et al., 2012), and has explored how the stereotypes of a single identity are predictive of discriminatory outcomes (Becker \& Asbrock, 2012; Sadler et al., 2015). There is a noted gap, however, in the workplace mental illness literature that offers a strong theoretical rationale for the outcomes associated with a unique stereotype resulting from intersectional identities (e.g., woman with mental illness). The current study contributes to workplace stigma literature by offering further understanding on the implications of unique stereotypes for workplace outcomes. This is accomplished by delving into the effects of both mental illness- and gender-related stereotypes as predictors of workplace outcomes. As perceived gender is a salient and easily detected identity in the workplace already associated with 
discriminatory outcomes and negative experiences (Eagly et al., 2000; Heilman \& Eagly, 2008), I seek to further understanding of how it interacts with mental illness — a less visible identity - to create unique stereotypes.

Existing workplace mental illness research utilizes the stereotype content model (SCM) to examine stereotyped identities. According to the SCM, individuals are evaluated as possessing different amounts of both competence (i.e., ability, intelligence) and warmth (i.e., friendliness, helpfulness) according to their apparent group membership (e.g., women, white-collar workers; Fiske et al., 2002). The model places groups into quadrants created from intersecting axes of competence and warmth (e.g., high competence-low warmth, low competence-low warmth). This can assume that both components of the stereotype exert equal influence over outcomes and disallows for examination of differential outcomes for each component. Although it is becoming more common for researchers to examine each dimension (e.g., competence and warmth) as a separate mechanism (see Martinez et al., 2016; Smith et al., 2016), most studies select the same outcome for each pathway, preventing examination of unique stereotype dimension-outcome relationships.

Additionally, the existing literature, as a whole, has demonstrated inconsistent findings on whether competence, warmth, or the combination is most predictive of differentiated affective and behavioral outcomes (e.g., prejudice and discrimination) for workers who have ambivalent stereotyped identities (i.e., stereotype of higher levels of one dimension and lower levels of the other; see Follmer \& Jones, 2018; Martinez et al., 2016; Sadler et al., 2012; Sadler et al., 2015; Smith et al., 2016). This is an integral puzzle to solve, as the majority of workers have ambivalent identities, and the influence 
of low competence will naturally not be equivalent to that of low warmth, nor will any potential bolstering from high evaluations of one dimension be consistent with the other. The current study contributes to workplace mental illness literature by exploring unique relationships between distinct workplace outcomes and mental illness through discrete pathways of competence or warmth evaluations, examining the potentially unique predictive strength of each stereotype component on differential workplace outcomes for individuals with ambivalent identities.

Empirical research on workplace mental illness stereotypes has demonstrated a large variation in findings. Although a majority of studies have found mental illness to be related to negative outcomes at work, the severity of the stereotype and the relationship with outcomes differ according to multiple influences (Follmer \& Jones, 2018). Some of this variability has been explained by differences between individual mental illnesses (e.g., anxiety, PTSD; see Sadler et al., 2012) and evaluator differences (e.g., social dominance orientation; see Follmer \& Jones, 2017) yet more variability remains. I propose a portion of the remaining error can be explained by the influence of the apparent gender of the target. Visible identities such as gender are automatically perceived, and hence, salient (Amodio et al., 2004; Eagly et al., 2000). Previous research has firmly established gender as a strong predictor of workplace stereotype and discrimination outcomes (Colella et al., 2017; Heilman \& Eagly, 2008). Further, in the evaluation of others, stereotypes are interactive and multiple identities are often automatically combined into a single unique identity by evaluators (Stangor et al., 1992). Hence, the current research contributes to workplace mental illness stigma research literature by 
examining gender as an omnipresent boundary condition that influences evaluations of workers with mental illness.

According to the Stereotype Content Model, people with mental illness are stereotyped as possessing low levels of competence and middle-to-low levels of warmth (Fiske et al., 2002; Sadler et al., 2012). Theoretically and empirically, competence evaluations predict passive behavioral reactions and warmth evaluations are predictive of active behaviors (Cuddy et al., 2007). Interpersonally, passive harming behaviors in the workplace that are associated with lower competence evaluations largely consist of exclusionary and ignoring behaviors, as these behaviors convey a desire for distance without appearing to violate explicit workplace norms (Colella et al., 2017; Cuddy et al., 2007; Hebl et al., 2008; Hershcovis, 2011). Active facilitation in the workplace associated with higher warmth perceptions may be enacted by choosing to work with someone or sharing resources with them (see Follmer \& Jones, 2017). Past research has empirically supported that people do not want to work with individuals holding stigmatized identities, to the extent that they explicitly request a different work partner when paired with an individual with a mental illness diagnosis (Lucas \& Phelan, 2019). Hence, the current study has identified ostracism (e.g., social exclusion, ignoring) and desire to work with an individual as outcome variables respectively associated with competence and warmth evaluations.

Men generally experience high status in the workplace that is associated with perceptions of high competence. This status can be fragile. When men act against their expected gender role by visibly managing mental illness, they experience backlash in terms of reduced competence evaluations from others (Moss-Racusin et al., 2010). 
Women who work already manage stigmatized identities due to their traditional stereotype and are afforded higher warmth at the cost of the devaluation of their competence (Fiske et al., 2002; Heilman et al., 2004). When women also manage mental illness, the unique stereotype resulting from the intersectional identity of their two identities (i.e., being women and having mental illness) has potential to reduce evaluations of their warmth due to the unpredictability associated with mental illness. Indeed, empirical research has demonstrated that gender interacts with stigmatized identities (e.g., race, sexual identity) in the workplace to predict differential effects on worker outcomes according to the resulting intersectional identity (see Martinez et al., 2016; Smith et al., 2016). Hence, I selected gender as a moderator to interact with mental illness in the current study.

\section{Present Research}

This research is critical for three reasons. First, as stigmatization of mental illness is related to negative perceptions of competence and warmth and resulting interpersonal outcomes, workers with mental illness have the potential to encounter roadblocks and limitations in their career trajectories, leading to reduced opportunities for skill development and consequently reduced likelihood of career advancement. These reduced opportunities and increased roadblocks may be initiated doubly through an increase in interpersonally discriminatory behaviors including ostracism (e.g., being ignored or neglected) and a reduction in interpersonal allying behaviors including befriending and sharing resources. Hence, workers with mental illness are likely to receive low levels of social support from coworkers. Second, this is a particularly problematic phenomenon as social support at work buffers the relationship between workplace stressors and strain 
symptoms. Hence, lack of social support increases the likelihood and severity of negative employee outcomes including anxiety, depression, and impaired concentration and memory (Griffin \& Clarke, 2011). Third, as workers with mental illness already manage emotional and cognitive impairment in their daily lives, the increased experience of exclusion from ostracism has the potential to exacerbate impairment-related symptoms. Hence, the potential for workers with mental illness in the workplace to experience a downward spiral of diminishing support and increased mental illness symptoms is profound.

The current research contributes theoretically to the field of workplace stereotype research through examination of nuances related to mental illness stereotypes. Application of the Stereotype Content Model to workers with mental illness in an online experimental format over multiple time points allows for close investigation of the individual constructs without potential contamination from variation in the target behavior. Identifying and testing differential predictive paths through separate stereotype components toward workplace interpersonal outcomes affords the opportunity to explore potential explanations for existing variability in the identity-stereotype-work outcome relations as reported in the current literature (see Fiske et al., 2002, Follmer \& Jones, 2017; Martinez et al., 2016; Sadler et al., 2012; Smith et al., 2016). Using theoretical evidence to guide the prediction of the influence of apparent gender to the process of managing mental illness contributes to the literature by exploring the complexity of an ever-present boundary condition. Furthermore, this study applies a broad model (e.g., SCM) to a specialized population, delving into the nuances of unique stereotypes associated with intersectional (e.g., interconnected social categories) identities resulting 
from the influence of both visible and hidden identities. Finally, confining the social sphere of this study to the workplace allows for further consideration of how reactions to these intersectional identities contribute to the occurrence of informal, and potentially unconscious, workplace interpersonal discrimination through evaluations of personal attributes (i.e., competence and warmth). 


\section{Chapter 2: Hypothesis Development}

\section{Stigma and the Stereotype Content Model}

Stigmas are discrediting attributes that signal a devalued identity (Goffman, 1963). Stigmatized identities may be visible (e.g., apparent gender) or they may be hidden (e.g., mental illness). Stereotypes are socially-held beliefs about groups or individuals within a group (e.g., the perception that individuals with mental illness are dangerous); prejudices are endorsement of and affective reactions to stereotypes (e.g., fear towards individuals with mental illness because they are perceived as dangerous); and discrimination is characterized as behaviors which may or may not be based on stereotypes and prejudices (e.g., ignoring a coworker with mental illness because of fear associated with the idea that they are dangerous, or ignoring them because you just don't like them even if you don't fear them or believe them to be dangerous; Dovidio et al., 2000).

The Stereotype Content Model explains differing societally-held beliefs about social groups and individuals within those groups (Fiske e al., 2002). Groups are evaluated along two intersecting continua: competence and warmth. These evaluations are an integral part of intergroup (i.e., between groups) and interpersonal (i.e., between individuals) interactions. In this sphere warmth reflects a person or group's intent to harm or benefit, representing their competitiveness, and competence reflects the person or group's ability to successfully pursue their goal, representing their status. Evaluations of both high warmth and high competence suggest a membership in a group that is communal or benevolent in intentions and able to successfully carry out those intentions (e.g., White people). Low warmth and high competence suggest membership in a group 
that is competitive or personally motivated and able to achieve their motivations (e.g., men). High warmth and low competence represent membership in a group that is benevolent but not effective in goal attainment (e.g., women). Finally, both low warmth and low competence represent membership in a group that is not benevolent and not effective (e.g., welfare recipients; Fiske et al., 2002).

Individuals with mental illness are consistently viewed as relatively low in competence (Fiske et al, 2002; Follmer \& Jones, 2018; Sadler et al., 2012). Mental illness stereotypes were originally included in the disability stereotype group, a category that is evaluated as low competence, high warmth due to their perceived lack of competitive motivations or ability for goal attainment (Fiske et al., 2002; Martinez et al., 2016). Once evaluated separately, mental illness ratings demonstrated distinction from disability, still exhibiting low competence, yet accompanied by a range of warmth ratings. Mental illness is generally associated with an average of low-to-middle explicit appraisals of warmth, due to the variability of warmth perceptions across mental illness conditions. General mental illness receives low warmth evaluations, lower than the individual evaluations of the most common mood disorders which are perceived as middle amounts of warmth (Sadler et al., 2012). Though the higher end of explicit warmth evaluations (i.e., close to middle-level ratings) have potential to compensate for the effects of lowered competence evaluations, implicit ratings of warmth for individuals managing mental illness have been found to be lower than explicit measures (Day et al., 2007). These findings suggest that the higher explicit evaluations of warmth in the literature may not accurately reflect internal evaluations. Regardless of assessment method, these findings demonstrate that individuals with mental illness are regularly evaluated as possessing lower levels of both 
competence and warmth. These findings hold true in the workplace, where workers with mental illness are also rated as relatively low in competence and warmth (Follmer \& Jones, 2018).

\section{Outcomes of Mental Illness Stereotypes}

The current stigma literature is inconsistent on whether competence or warmth ratings are more predictive of attitudinal and behavioral responses towards stigmatized individuals (Richetin et al., 2012). In the SCM, perceptions of competence are influenced by status and perceptions of warmth are influenced by competition. The combined stereotype identity (e.g., low-competence/high-warmth reflecting a person who is low status but not competing for resources) is predictive of reactionary behaviors, such as passively ignoring or actively assisting, depending on which dimension is emphasized (Fiske et al., 2002). The Behaviors from Intergroup Affect and Stereotypes (BIAS) map explains how stereotypes in the SCM predict behaviors (Cuddy et al., 2007). Behaviors resulting from stereotypes vary in intensity (e.g., passive to active) and valence (e.g., facilitating to harming) according to the respective level of the stereotype dimension.

\section{Competence-Related Outcomes}

According to the BIAS map, competence stereotypes predict passive behaviors (Cuddy et al., 2007). Interestingly, the effects of competence and warmth in predicting behaviors of evaluators towards a target are altered by the saliency of the stereotype dimension. When competence is emphasized, a worker who manages a lower competence stereotype will receive passive harming behaviors from others, regardless of warmth evaluations (Becker \& Asbrock, 2012). Further, when evaluating strangers, impressions 
of their competence are strongly predictive of interpretations of and reactions to their behavior (Richetin et al., 2012). Due to current business trends of advancing technology, an expanding global marketplace, and shortened organizational tenure, employees are more likely than ever to be employed by large organizations, work remotely, or experience high turnover in their employment (Cascio \& Aguinis, 2011; Noe, 2020). Hence, many coworkers are little more than acquaintances. Due to the double effects of a competence-salient environment and lack of close relationships, the stereotype-related perception of a person's competence becomes particularly influential in the workplace, even if it contradicts objective measures of their actual competence or intelligence. Furthermore, owing to the high-level salience of competence in the workplace, regardless of perceptions of their warmth, workers with mental illness may potentially experience more negative interpersonal consequences at work related to their competence stereotypes.

Behaviors based on stereotypes of lower competence are reflective of motivations to avoid the person (Sadler et al., 2015). Specifically, as competence is related to passive behaviors and the level of perceived competence determines whether social partners' behaviors help or harm, workers perceived as possessing lower competence are likely to receive passive behaviors that are harmful. This can manifest in the workplace as ostracism, exclusionary behaviors that allow individuals to avoid a specific person without appearing to violate workplace social norms. Though ostracism is a passive behavior, it has been connected to a variety of negative outcomes for the individual being impacted. When experiencing ostracism, individuals have reduced opportunities to benefit from social networks that provide interpersonal, informational, and task-oriented 
support (Robinson et al., 2013). As workers managing mental illness are viewed as less competent than their coworkers, they are likely to experience ostracism in their workplaces.

Given this rationale and the aforementioned rationale regarding competence stereotypes resulting from mental illness status, I propose the following hypothesis.

Hypothesis 1: Evaluations of competence will mediate the relationships between mental illness status and passive harm outcomes such that, relative to workers without mental illness, workers with mental illness will receive ratings of lower competence which will lead to higher endorsement of ostracism intentions by evaluators (presumed coworkers).

\section{Warmth-Related Outcomes}

In the majority of social science research, warmth has demonstrated primacy over competence in predicting harming behaviors (Richetin et al., 2012). The BIAS map posits that warmth stereotypes specifically predict active behaviors, which are likely to occur in the workplace where individuals work together to achieve group goals (Cuddy et al., 2007). Additionally, when made salient, warmth evaluations predict outcomes regardless of competence stereotypes (Becker et al., 2012). As warmth perceptions reflect the cooperative or competitive nature of an individual, employees working toward a common goal will prefer to associate with those they perceive as cooperative or benevolent, and not competitive. When an individual is perceived as warmer, others are likely to provide active facilitation (Cuddy et al., 2007). In the workplace, active facilitation can manifest as choosing to associate with a coworker, inviting them into a social group and by 
extension, providing them with a variety of resources to facilitate their interpersonal interactions and career path. Accordingly, coworkers may be less likely to help a person they view as less warm. As demonstrated by Follmer \& Jones (2017), workers are less likely to actively choose to extend facilitating behaviors (e.g., mentoring) to coworkers they evaluated as lower in warmth, relative to those evaluated as higher in warmth, due to their mental illness stereotype. These findings demonstrate that warmth perceptions predict the degree to which others intend to facilitate an individual at work.

Stereotypes of lower warmth are directly related to concerns over interpersonal unpredictability, such that workers with mental illness are considered to be less able to work successfully in teams and resolve interpersonal conflict, lending an unpredictable nature to their interpersonal reactions and behaviors (Sadler et al., 2012, Sadler et al., 2015). Relatedly, workers managing mental illness are considered to be less able to handle criticism or control their emotions (Hand \& Tryssenaar, 2006). These factors increase the likelihood that coworkers would consider them to be interpersonally unpredictable and decrease the likelihood that they would choose to associate with them. An online experimental study recently demonstrated this, finding that after completing a first project task together with fictitious partners, fewer participants requested to work with the same partner a second time when that partner was identified as managing a mental illness (Lucas \& Phelan, 2019). This preference existed even though interactions were qualitatively equivalent across conditions. Similar to this study, the present research focuses on desire to work with the focal individual with or without mental illness as an indicator of active facilitation behavior. 
Given this rationale and the aforementioned rationale regarding warmth stereotypes resulting from mental illness status, I propose the following hypothesis.

Hypothesis 2: Evaluations of warmth will mediate the relationships between mental illness status and interpersonal outcomes such that, relative to workers without mental illness, workers with mental illness will receive ratings of lower warmth, which will lead to lower desire to work with the individual.

\section{Gender and Mental Illness}

The intersection of mental illness and gender stereotypes has the potential to lead to differential negative effects on an employee's work experiences and career path. When evaluated on a unique stereotype resulting from intersecting identities, consequences for workers with mental illness who also hold another devalued identity (e.g., being a woman) may be greater relative to workers who only hold one devalued identity. There are multiple societally-held stereotypes associated with an individual's perceived gender which are different from mental illness stereotypes. When the visible stereotype associated with gender is combined with a hidden mental illness stereotype, the interaction of stereotypes against these workers holds greater potential to harm some individuals through creation of unique stereotypes. These workers experience intersectionality, a phenomenon that occurs when individuals who manage two stigmatized identities often experience outcomes that are different than what would result from the additive values of their individual identities (Crenshaw, 1991). For many individuals, the unique stereotype of combined identities can result in consequences that are greater in magnitude than would be expected from the additive consequences from stereotypes of the multiple groups to which they belong. This negative effect of multiple 
stigmatized identities may be particularly relevant when the visual saliency of one identity serves to prime the unique stereotype. Accordingly, as visible identities such as gender are automatically perceived and people containing multiple social identities may be evaluated on a unique combination of the identities (Amodio et al., 2004, Stangor et al., 1992). Hence, employees assessed on a unique intersectional identity resulting from both mental illness and gender stereotypes may encounter consequences in the form of reduced access to resources for managing work demands and fewer social networks to provide opportunities for learning or advancement, contributing to a decreased likelihood of promotions and successful career paths.

According to gender role theory, a person's apparent gender dictates specific prescriptive (i.e., what one should do) and proscriptive (i.e., what one should not do) behaviors. Men and women have different expected roles according to their traditional place in society. Acting in accordance with one's gender leads to approval (Eagly, 1987; Eagly et al., 2000). Violation of either prescriptive or proscriptive behaviors will lead to negative evaluations of that person and may cause strong negative consequences through backlash (i.e., a strong, adverse reaction) based on the perceived severity of the violation (Moss-Racusin et al., 2010).

\section{Intersectionality for Men}

Stereotypically, men benefit from an elevated status associated with higher competence and lower warmth stereotypes (Fiske et al, 2002). However, the higher status associated with higher competence for men is dependent upon maintaining masculinity stereotypes ascribed in gender role theory (Eagly, 1987; Eagly et al., 2000). Hence, men are expected to be competitive and personally motivated, in addition to exhibiting agentic 
behaviors to accomplish their goals. They are not expected to be communal or need help to succeed. When a man acknowledges managing a mental illness, an incongruity is created between the status and according competence stereotypes in the two facets of his unique identity; the status associated with mental illness is much lower than that with his gender. As competence evaluations reflect status, the loss of status as a result of the discrepancy between a man's two individual identity facets can cause his unique identity to be stereotyped as lower in competence (Eagly et al., 2000). Additionally, as an individual managing a mental illness, he violates both the prescriptives (by not being able to successfully reach goals) and proscriptives (by needing help from others) of his expected gender role. In addition to the reduction in competence caused by the discrepancy of incongruent identity facets, he will likely experience an even greater penalty to competence evaluations through backlash reactions to his perceived role violation (Moss-Racusin et al., 2010). Hence, men managing mental illness at work have a great potential to experience a reduction in competence evaluations.

Given the aforementioned rationale regarding intersectionality for men and in general, I propose the following hypothesis.

Hypothesis 3: Gender will moderate the relationship between mental illness status and competence, such that the effect of mental illness will be stronger for men.

\section{Intersectionality for Women}

According to the SCM, women are traditionally stereotyped as possessing lower competence and higher warmth. Agentic women in the workplace, however, are 
stereotyped as the opposite of traditional women; they are afforded higher competence, but the violation of their communal gender role leads to lower warmth evaluations (Fiske et al., 2002). This reversal does not hold consistent for all women who work, though. Rather it primarily affects women whose actions are interpreted as a violation of the prescriptives and proscriptives associated with their traditional role: women who are leaders, employed in male-dominated fields, or who demonstrate specifically agentic and masculine behaviors (Heilman et al., 2004). As such, though women may be employed, if they are not viewed as behaving in a manner that violates their prescribed gender role, they will likely retain the traditional stereotype of higher warmth with lower ratings of competence. Interestingly, though recent research demonstrates that evaluations of women's competence have raised over the past 70 years due to their increasing representation in work settings (Eagly et al., 2019), when explicitly compared to male coworkers, evaluators rated women as lower in intelligence regardless of their apparent agentic behaviors (Reilly et al., 2017). This finding suggests that regardless of which ambivalent stereotyped identity women possess (e.g., traditional or agentic), evaluations of a single stereotype dimension (e.g., competence) of their unique identity may be influenced by the identity facet that holds the lower value of that specific dimension.

The traditional higher warmth associated with stereotypes for women reflects communal and benevolent characteristics according to a woman's expected social role (Eagly, 1987). When a woman acknowledges managing a mental illness, the inherent unpredictability associated with mental illness prevents others from being able to judge her apparent personal motivations and decreases the perception that she is acting for the betterment of the group. In the workplace, motivations to benefit the group (e.g., work 
team, department, organization) are integral to success. Thus, a reduction to warmth or likability would be the cost of the unpredictability associated with a woman who manages mental illness. Hence, a discrepancy occurs for warmth perceptions between individual facets of the identity of a woman managing mental illness. This discrepancy should result in lower evaluations of warmth for the individual. Additionally, the unpredictability directly violates a gender role expectation, as the influenced worker can no longer fulfill their role as a communal and benevolent individual. This violation leads to a larger cost to warmth for women through backlash.

Given the aforementioned rationale regarding intersectionality for women and in general, I propose the following hypothesis.

Hypothesis 4: Gender will moderate the relationship between mental illness status and warmth, such that the effect of mental illness will be stronger for women.

\section{Outcomes for Men}

As individuals with higher status in the workplace, men experience a higher frequency of positive outcomes than women (Davidson \& Burke, 2000). Additionally, men are often viewed as more competent than women colleagues, particularly if they are in leadership positions. Since these positive outcomes and evaluations are dependent upon their higher status, violations of their gender role prescriptives and proscriptives through acknowledgement of mental illness can lead to negative reactions associated with perceived reductions in competence and status (Moss-Racusin, 2014; Moss-Racusin et 
al., 2010). Hence, they are likely to experience stronger passive harm in the form of interpersonal mistreatment related to lower evaluations of competence.

Men with mental illness are likely to have their ideas ignored by work partners, an act of passive harm similar to ostracism (Cuddy et al., 2007; Kroska et al., 2015). Indeed, when expressing distancing intentions for coworkers with mental illness, respondents indicate greater distancing intentions for men than for women, and men have experienced ostracism as a result of violating gender roles (Berdahl, 2007; Follmer \& Jones, 2017).

Given this rationale, the aforementioned rationale on the mediational effect of competence in the mental illness — ostracism intention relation (Hypothesis 1) and that on the moderational effect of gender on the mental illness - competence relation (Hypothesis 3), I propose the following hypothesis.

Hypothesis 5: Gender will moderate the mediation between mental illness status, competence, and interpersonal outcomes, such that relative to women, men with mental illness will receive ratings of lower competence which will lead to higher endorsement of ostracism intentions by evaluators (presumed coworkers).

\section{Outcomes for Women}

Reactions to women who have an ambivalent stereotype are primarily based on their lowest stereotype dimension — warmth or competence (Heilman et al., 2004). Hence, regardless of which gender stereotype is endorsed for women (e.g., traditional or agentic), they are likely to experience negative outcomes. When women holding a unique identity (e.g., being women and having mental illness) are evaluated however, the intersectionality of their identity and subsequent stereotype elicits different reactions than 
their singe identity would (Crenshaw, 1991). Traditionally, women receive active facilitation in the workplace as a response to higher warmth evaluations. Particularly, they are befriended and invited into social networks due to their perceived lack of competitive nature. As women already experience unequal workplace experiences, including lower pay and fewer promotions (Colella et al., 2017; Heilman \& Eagly, 2008), these social networks may provide compensatory resources to help them navigate their careers through informal channels. Since women managing a mental illness are viewed as less warm due to the unpredictability of their motivations and reduction in communal intentions, people are less likely to want to befriend or work with them. Hence, they are likely to receive fewer invitations to social networks due to their higher potential for competition for workplace resources.

Given this rationale, the aforementioned rationale on mediational effect of warmth in the mental illness — ostracism intention relation (Hypothesis 2) and that on the moderational effect of gender on the mental illness - warmth relation (Hypothesis 4), I propose the following hypothesis.

Hypothesis 6: Gender will moderate the mediation between mental illness status, warmth, and interpersonal outcomes, such that relative to men, women with mental illness will receive ratings of lower warmth which will lead to lower desire to work with the individual. 
Chapter 3: Methods

\section{Participants \& Procedure}

Employed adults were recruited via Qualtrics panel, an online participant recruitment and survey platform that compensates participants for completing surveys. In a recent analysis, samples recruited from Qualtrics panels were representative of national demographics and political affiliations (Boas et al., 2020). Though some individuals have voiced concern over internal validity of panel data, Qualtrics requires participants to correctly answer quality assurance questions and replaces all data identified as below acceptable quality levels. Participants were required to be over 18, working at least 20 hours each week, located in the United States, and able to read English. In all, 821 participants successfully completed Time 1 data collection and correctly responded to the embedded instructed response items. Qualtrics replaced 43 respondents identified as below acceptable level of quality, as recommended by Huang and colleagues (2014), with a completion time of under two seconds per item. Hence, 821 participants were eligible to complete Time 2 data collection. Time 2 collection yielded 372 participants who successfully completed data collection procedures. After removal of 14 irresponsible responders identified by Huang and colleagues' (2014) criteria, 358 participants remained. The final sample contained 242 participants, after participants who were assigned to an experimental condition unrelated to current study were removed. Participants in the final sample were $50.4 \%$ women and $86.4 \%$ White with an average age of 45.68 years $(S D=14.36)$.

The two online surveys were three weeks apart. Participants were paid $\$ 6$ for successfully completing each time point. During Time 1, participants completed short 
surveys to measure aspects of their mental illness stigmatizing beliefs and demographic information (see Appendix A). As previous research has found that evaluator attitudes influence perception of and reactions to individuals with mental illness (see Follmer \& Jones, 2017), stigmatizing beliefs were collected to use as control variables in all hypothesized models. The survey materials for this time point include an instructed response item that participants were required to correctly answer to complete the survey and be included in the pool of respondents for Time 2. In order to reduce contamination effects and common method bias, Time 2 participants were recruited from the pool of respondents to Time 1 , but the recruitment, stimulus, and survey materials in Time 2 did not refer to Time 1. Additionally, the informed consent form and study title for each time point was different, referring to only the procedures occurring within the current time point.

Time 2 participants read an introductory paragraph instructing them to imagine that they are a new hire in a sales team and are evaluating the members of the team (see Appendix B). In particular, they evaluated the ability of one team member, the target, to integrate back into the team after five weeks of leave. They read a welcome email from the target and watched a screenshot recording of a chat-style meeting between the target and the target's work partner (see Appendix B). After these activities, participants rated characteristics of the target and then completed measures indicating their future intentions to socially exclude the target through ostracism and their desire to work with the target (see Appendix A). The job description and specific industry in the stimulus materials were purposely left vague so that participants could use personal work experience to imagine fitting into the team. The target's sales role was chosen to avoid 
potential gendered job role contamination, as women make up about $39-47 \%$ of the current US sales job positions (Women's Bureau, 2018).

In the Qualtrics platform, participants were randomly assigned to one of four conditions (mental illness status: yes vs. no X gender: woman vs. man). The mental illness status condition was manipulated with a phrase indicating the reason for leave in the introductory paragraph and the email. Gender was manipulated through the name of the target, which appeared in the introductory paragraph, email, and chat meeting (see Appendix B). Near the end of the survey, participants were asked to select the reason for the target's leave from multiple choices. If they responded incorrectly, they were removed from the survey without completing. The number of removed responses were not provided to me by Qualtrics. The survey materials for this time point also included two instructed response items that participants had to correctly answer to complete the survey.

\section{Power Analysis}

A review of 30 years of research by Aguinis, Beaty, Boik, and Pierce (2005) examined the effect sizes of categorical moderators in multiple regression models through the calculation of a modified $f^{2}$, a representation of the variance accounted for by the categorical moderator compared to the remaining variance in the outcome. The authors detected an average, observed moderation effect size of $f^{2}=.009($ Mean $=.009$, Median $=.002)$, and construct level effect size of $f^{2}=.017($ Mean $=.017$, Median $=.003)$. Further, they noted that effect sizes increased along with the 30 years of studies in review, with more recent studies attaining larger effect sizes, partially due to advances in reduction of artifacts. Power for moderated mediation models is acceptable at .84 when 
detecting an effect of $f^{2}=.02$, considered a small effect size (Aguinis et al., 2005).

Previous experimental studies examining moderation and moderated mediation models of stigmatized identities have indeed found small to medium effect sizes (see Martinez et al., 2016; Smith et al., 2016). Preacher, Rucker and Hayes (2007) indicate that, when using bootstrapping, to detect a small effect $(r=.14)$ at alpha $=.05$, the sample size needs to be at least 400 . To obtain this overall sample over the two time points in the proposed study, I recruited 800 participants at Time 1 to allow for $50 \%$ attrition between time points. Due to larger than expected attrition and the presence of a third experimental condition outside the scope of the current study, the final sample size was 242 . This provided acceptable power to detect mediational relationships with small effect sizes (Preacher et al., 2007), but lacked the power for moderational and moderated mediation models with a small effect.

\section{Materials}

\section{Introductory paragraph}

Introductory paragraphs were identical across all conditions with two exceptions. To manipulate apparent gender, the worker was introduced as either Ann or Andrew. Target names were selected to reflect the dominant racial and cultural group (e.g., White, likely Christian) to prevent contamination of unique stereotypes. To manipulate mental illness status, the reason provided for five weeks of leave was identified as either a mental health condition or a car accident. A car accident was chosen for the non-mental illness condition to create a similar theme (e.g., involuntary health leave) to mental illness without the associated stigma of a chronic condition. See Appendix B for all stimulus materials (i.e., introductory paragraph, email, meeting transcript). 
Email

The emails were identical across all conditions with the same two exceptions as the introductory paragraph. Apparent gender and mental illness status manipulations remained consistent with manipulations utilized in the introductory paragraph. The email was neutrally worded, neither warm nor rude. A subject matter expert (SME) consulted on email content and word choice to ensure validity.

\section{Meeting}

The meetings were identical across all conditions with one exception. To manipulate apparent gender, the worker was either referred to as Ann or Andrew and the coworker was either referred to as Janet or John. The target and coworker had consistent apparent gender within each team (e.g., Ann/Janet or Andrew/John). The meeting was a silent screen recording of a chat-style software (e.g., Slack, Google Hangouts). In the meeting, the background for the sales team and the goals for the future were stated. The health leave was referred to in the beginning and end of the meeting. For the remainder of the meeting, the target and coworker generated ideas for creating sales. Each member of the team proposed an equal number of ideas of equivalent quality. Three SMEs consulted on creation of this stimulus material. An experienced sales executive consulted to ensure face validity of content and word choice, one industrial/organizational (I/O) psychologist consulted to ensure accurate representation of communication regarding mental illness, and one other I/O psychologist consulted on accurate representation of a target neutral in both personality and work performance.

\section{Measures}


Competence and warmth. Competence and warmth were measured using the Competence and Warmth Scales created by Fiske, Cuddy, Glick, and Xu (2002). Competence was measured with five items $\left(\alpha_{c}=.84\right)$ on a 5-point scale $(1=$ Not At All to $5=$ Extremely). A sample item is "[Name] is intelligent." Warmth was measured with four items $\left(\alpha_{\mathrm{w}}=.89\right)$ on the same 5-point scale as for competence. A sample item is "[Name] is good natured."

Ostracism intentions. Ostracism intentions were measured using an adapted version of the Supervisor-Reported Ostracism Behavior Scale created by Wu, Ferris, Kwan, Chiang, Snape, and Liang (2015). The adapted version changed the verb tense of the items from past to future. Ten items were measured on a 7 -point scale $(1=$ Never to 7 $=$ Always; $\alpha=.97)$. A sample item is "I would avoid [NAME] at work."

Desire to work with target. Desire to work with target was measured using three individual items. As this outcome is often measured with a single item, I drew example items from organizational diversity literature (see Lyons et al., 2016), and combined and adapted them with guidance from two organizational research experts into a three-item scale $(\alpha=.96)$. Three items were measured on a 5 -point scale $(1=$ Not At All to $5=$ Very Much). A sample item is "How much would you want to work with [NAME] every day?"

Demographics. In addition to demographic information of gender, age, ethnicity, education, income, and marital status, three questions gathered expanded information (e.g., experiences with mental illness and LGBT identification) for potential future exploratory analyses. 
Covariate: Mental illness stigma. Mental illness stigma was measured using an adapted version of the Personal Depression Stigma Scale created by Griffiths, Christensen, Jorm, Evans, and Groves (2004). The adapted version of the scale replaces “depression” with "mental health pronlem.” Participants were instructed to respond to nine items on a 7 -point scale $(1=$ Strongly Disagree to $7=$ Strongly Agree; $\alpha=.87)$. A sample item is "People with a mental health problem are unpredictable." Please see Appendix A for all measures. 


\section{Data Quality}

\section{Chapter 4: Results}

After the quality response filters described in the Methods section were utilized, I examined two forms of missingness of the data: (a) participant attrition between time points and (b) item and scale missingness within each time point. Logistic regression and chi-square analyses revealed that no demographic variables (e.g., gender, age, race, sexuality), nor the mental health stigma scale measure collected at Time 1 were statistically associated with presence or absence at Time 2. Please refer to Table 1 for results from logistic regression and chi-square analyses. Additionally, the responses of all participants in this sample were complete, with no missing data for any of the items or scales. Though this may seem unusual, respondents from Qualtrics panels are compensated at a higher rate than other online survey completion platforms (e.g., MTurk), and the quality of the respondents' answers directly influence their ability to participate in future panels, motivating participants to ensure their responses are of acceptable quality.

\section{Descriptive Statistics}

I examined data at the item level to ensure that there were no immediately visible problematic items (e.g., responses displaying patterns opposite of theoretically and empirically based expectations). Next, I examined reliability and factor structure of each scale. All scales demonstrated levels of reliability of Cronbach's alpha above .80 , appropriate for basic experimental research (Nunnally, 1978). Specific reliability values are reported in Table 2. Confirmatory factor analyses (CFAs) were completed in Mplus using maximum likelihood estimation for warmth and desire to work with scales and 
maximum likelihood mean-centered estimation for all other variables (version 8; Muthén \& Muthén, 2017). Individual CFAs for each focal scale reflected appropriate loading of individual items above .40 onto respective factors and acceptable fit indices. Please see Table 3 for fit statistics of individual measures. Finally, I verified that all scales measured distinct constructs by examining the fit of nested CFAs in three steps. All models were estimated with Satorra-Bentler (1998) corrections for maximum likelihood mean-adjusted chi-square due to violations of normality. In the baseline one-factor model, I placed all items into one factor structure. This model did not indicate consistently appropriate item loadings, nor did any fit indices indicate acceptable model fit. My second model included four factors. Each scale was separated into a dedicated factor with the exception of competence and warmth perceptions, which were combined onto one single factor. This model demonstrated better fit than the baseline model, indicated by the change in chisquare. This model demonstrated significantly better fit than the alternate four-factor model as shown by the change in chi-square values. Finally, I tested a five-factor model, assigning each scale to a separate factor. This model demonstrated significantly better fit than the previous four-factor model and demonstrated the best fit indices, $x^{2}=659.13, \mathrm{CFI}$ $=.95, \mathrm{RMSEA}=.05, \mathrm{SRMR}=.07$. Please see Table 4 for full results from the nested CFA models.

Once scale structures were established, I obtained descriptive statistics and correlation for all scales. Please see Table 2 for mean, standard deviation, and correlation values for all scales. I explored normality of variables visually through boxplots, histograms, and q-q plots, and through descriptive statistics. Most variables demonstrated no notable violations of normality assumptions, with the exception of ostracism 
intentions. The distribution of ostracism intentions was leptokurtic (kurtosis $=16.65, S E$

$=.31$ ) and right skewed (skewness $=3.88, S E=.16$ ), due to fewer endorsements of

higher points of the Likert scale for all items in the measure. Since this distribution is not uncommon for measures of ostracism and other forms of workplace mistreatment (see Yang \& Caughlin, 2017; Yang et al., 2012), analysis procedures that utilized bootstrapping (i.e., indirect effects models in the PROCESS macro for SPSS), a remedy for violations of normality (Chernick et al., 2011), were planned a priori. In addition to non-normality, I found indications of multiple outliers on the ostracism intentions scale and two outliers each on the target competence and desire to work with target scales. I elected not to remove any outliers previous to analyses, however, as the multiple quality filters I employed decrease the likelihood that the outliers indicate quality issues and increase the likelihood of indication of genuine participant responses. Finally, I assessed diagnostic residual plots for possible violations of homoscedasticity assumptions for regression analysis. Most scales demonstrated homoscedasticity, except for ostracism intentions, where residual plots indicated heteroscedasticity. Specifically, residual values were greater for participants assigned to the mental illness and woman gender conditions, indicating unequal variance according to treatment condition. As bootstrapping offers an accepted remedy for heteroscedasticity (see Chernick et al., 2011), the planned analyses sufficiently addressed potential bias in results and no transformations were employed. ${ }^{1}$

\footnotetext{
${ }^{1}$ Hayes recommends that robust standard errors be computed when heteroscedasticity is present in a tested model. According to Long and Ervin (2000), the HC3 correction is appropriate for heteroscedasticity with under 250 cases. Analyses for models including ostracism intentions were conducted both with and without the correction. Results did not change using the correction, so I reported results from uncorrected analyses for two reasons: (a) when results are equivalent, parsimonious models are preferred, and (b) uncorrected analyses allow for comparisons of our results with those reported in the literature based on the same method.
} 


\section{Hypothesis Testing}

I conducted all hypothesis testing using Hayes' PROCESS Macro for SPSS (Hayes, 2017). The macro accepts categorical predictors and moderators and uses listwise deletion when individual cases are missing data. PROCESS also uses percentile bootstrapping when obtaining confidence intervals for indirect effects, which can correct for kurtosis, skewness, and heteroscedasticity in data (Hayes, 2017). Hypotheses 1 and 2 were analyzed using PROCESS Model 4 (simple mediation). Hypotheses 3 and 4 were analyzed with the PROCESS macro's Model 1 (moderation with a single moderator). Finally, Hypotheses 5 and 6 were analyzed with the PROCESS macro's Model 7 (moderated mediation with a single moderator on the 'a' path). All models testing mediational hypotheses (i.e., hypotheses $1,2,5, \& 6$ ) simultaneously tested the alternate mediator within the same rigorous model to account for the potential influence of the alternate mediator. Specifically, Hypotheses 1 and 2 were tested using PROCESS model 4 with simultaneous mediators of warmth and competence, and Hypotheses 5 and 6 were tested using the same simultaneous mediators in PROCESS model 7. Hence, results in the hypothesis test and alternate mediator subsections reflect results from the same analyses. Consequently, results in the alternate mediator section are shortened. Finally, mental illness stigmatizing beliefs were entered as a covariate in all models to control for potential influence, as past research has found that participant beliefs influence stereotype endorsement and mistreatment intentions (e.g., Follmer \& Jones, 2017).

To test the hypothesis that participants' competence perceptions of the target mediated the relationship between target mental illness status and participant ostracism intentions toward target, I conducted a mediational analysis, including warmth as a co- 
mediator in the model and mental illness stigmatizing beliefs as a covariate. Mental illness status did not significantly predict ostracism intentions directly, $\mathrm{B}=-.05, S E=.11$, $\beta=-.03, p=.644,95 \%$ CI $[-.26, .16]$, nor indirectly through competence perceptions, indirect coefficient $=.004, S E=.02, \beta=.002,95 \%$ CI $[-.03, .04]$. Mental illness status did not significantly predict competence, $\mathrm{B}=.05, \mathrm{SE}=.09, \beta=.03, p=.596,95 \% \mathrm{CI}[-$ $.12, .21]$, nor did competence significantly predict ostracism intentions, $\mathrm{B}=.08, S E=.11$, $\beta=.06, p=.498,95 \%$ CI $[-.15, .30]$. Accordingly, mean and standard deviation scores of competence were nearly identical for both the mental illness $(M=3.25, S D=.61)$ and car accident condition $(M=3.21, S D=.71)$ as were mean scores of ostracism intentions for both the mental illness condition $(\mathrm{M}=1.33, \mathrm{SD}=.76)$ and car accident condition $(\mathrm{M}=$ 1.34, $\mathrm{SD}=1.00)$. Hence, Hypothesis 1 was not supported. Please see Table 5 for descriptive statistics by treatment group and Table 6 for all mediational analyses results.

I conducted a mediational analysis to examine whether a participant's desire to work with the target was predicted by the target's mental illness status through the participant's perception of the target's warmth. The indirect effect through warmth was not significant as demonstrated by the indirect coefficient, $\mathrm{B}=.02, S E=.04, \beta=.01$, 95\% CI $[-.20, .10]$. Further, though mental illness status did not demonstrate a significant relationship with warmth perceptions, $\mathrm{B}=.05, S E=.09, \beta=.04, p=.571,95 \% \mathrm{CI}[-.13$, .23], warmth perceptions did significantly and positively predict desire to work with the target, $\mathrm{B}=.40, S E=.10, \beta=.27, p=.001,95 \% \mathrm{CI}[.20, .59]$, such that participants expressed greater desire to work with targets they perceived as warmer. Hence, Hypothesis 2 was not supported. Interestingly, the direct effect of mental illness status on desire to work with the target was significant, $\mathrm{B}=-.21, S E=.10, \beta=-.10, p=.037,95 \%$ 
CI [-.41, -.01], indicating that participants expressed less desire to work with targets managing mental illness. Accordingly, the mean and standard deviation of warmth did not differ for participants in the mental illness $(M=3.49, S D=.64)$ and car accident conditions $(M=3.46, S D=.74)$, though the mean of desire to work with the target did differ for mental illness $(M=3.56, S D=1.00)$ and car accident conditions $(M=3.76, S D$ $=1.00)$.

I completed a moderation analysis to examine whether the gender of the target moderated the effect of the target's mental illness status on their perceived competence, such that men with mental illness were rated as lowest in competence. Competence was not predicted by target mental illness status, $\mathrm{B}=.27, S E=.27, \beta=.03, p=.324,95 \% \mathrm{CI}$ $[-.27, .79]$, or target gender, $\mathrm{B}=.44, S E=.27, \beta=.16, p=.111,95 \% \mathrm{CI}[-.10, .97]$. Furthermore, the interaction term created from target mental illness status and gender did not significantly predict competence perceptions of the target, $\mathrm{B}=-.15, S E=.17, \beta=$ $.06, p=.383,95 \% \mathrm{CI}[-.48, .18]$. I next examined target gender as a moderator of the relationship between target mental illness status and perceptions of target warmth to examine whether women with mental illness would be rated as lowest in warmth. Neither target mental illness status, $\mathrm{B}=.07, S E=.28, \beta=.03, p=.816,95 \% \mathrm{CI}[-.49, .63]$, target gender, $\mathrm{B}=.16, S E=.29, \beta=.10, p=.572,95 \% \mathrm{CI}[-.41, .73]$, nor the interaction between the two conditions, $\mathrm{B}=-.01, S E=.17, \beta=-.005, p=.942,95 \% \mathrm{CI}[-.36, .34]$, demonstrated a significant relationship with perceptions of target warmth. Hence Hypotheses 3 and 4 were not supported. Please see Table 7 for full results from moderation analyses. 
I next examined the conditional effect of target gender on the indirect effect of target mental illness status on ostracism intentions toward target through perceptions of target competence (i.e., moderated mediation with moderator on "a" path). The moderated mediation was non-significant, index of moderated mediation $=-.01$ (standardized index $=-.006), S E=.04,95 \% \mathrm{CI}[-.10, .05]$, indicating no significant difference between the non-significant indirect effects for targets who were women, $\mathrm{B}=$ $.001, \beta=-.0005, S E=.02,95 \% \mathrm{CI}[-.05, .03]$, and men targets, $\mathrm{B}=.01, S E=.03, \beta=$ $.005,95 \%$ CI $[-.04, .08]$. Thus, Hypothesis 5 was not supported. Table 8 contains full results from moderated mediational analyses.

Finally, I explored the conditional effect of target gender on the indirect effect of target mental illness status on desire to work with the target through perceptions of target warmth (i.e., moderated mediation with moderator on "a" path). The moderated mediation was non-significant, index of moderated mediation $=-.001$ (standardized index $=-.0005), S E=.08,95 \%$ CI $[-.16, .15]$, indicating no significant difference between the non-significant indirect effects for targets who were women, $\mathrm{B}=.02, S E=.05, \beta=.01$, $95 \% \mathrm{CI}[-.07, .13]$, and men targets, $\mathrm{B}=.02, S E=.06, \beta=.01,95 \% \mathrm{CI}[-.08, .15]$. Thus Hypothesis 6 was not supported.

\section{Alternate Mediators}

Alternate mediators were examined for Hypotheses 1, 2, 5, and 6, such that models that tested competence as a hypothesized mediator also simultaneously tested warmth as a co-existing mediator. The opposite was conducted for models that proposed warmth as a mediator. Specifically, perception of target warmth was examined as an alternate mediator for Hypotheses 1 and 5 in the relationship between target mental 
illness status and ostracism intentions toward target. Accordingly, perception of target competence was examined as an alternate mediator for Hypotheses 2 and 6 in the indirect relationship between target mental illness status and desire to work with the target. These were introduced to the models as co-mediators to examine the effect of the variables simultaneously.

As an alternate mediator for Hypothesis 1, warmth was not a significant mediator of the indirect relationship between target mental illness status and ostracism intentions toward target, $\mathrm{B}=-.02, S E=.03, \beta=-.01,95 \% \mathrm{CI}[-.10, .04]$. Additionally, mental illness status did not predict warmth perceptions, $\mathrm{B}=.05, S E=.09, \beta=.04, p=.571$, 95\% CI $[-.13, .23]$. Warmth perceptions did significantly predict ostracism intentions, B $=-.34, S E=.11, \beta=-.26, p=.002,95 \%$ CI $[-.55,-.12]$, however, indicating that for the current sample, perceptions of a target's warmth may influence ostracism intentions towards a potential coworker. Please refer to Table 6 for full mediational results.

Though explored as a potential alternate mediator for Hypothesis 2, competence was not a significant mediator of the indirect relationship between target mental illness status and desire to work with the target, $\mathrm{B}=.29, S E=.06, \beta=.01,95 \% \mathrm{CI}[-.08, .14]$. Additionally, mental illness status did not predict competence perceptions, $\mathrm{B}=.05, S E=$ $.09, \beta=.03, p=.596,95 \%$ CI $[-.12, .21]$. Competence perceptions did significantly predict desire to work with the target, $\mathrm{B}=.64, S E=.10, \beta=.42, p<.001,95 \% \mathrm{CI}[.43$, .85], such that participants' desire to work with the target increased accordingly with higher perceptions of the target's competence. This indicates that for the current sample, perceptions of competence may influence desire to work with a potential coworker. 
When examining warmth as an alternate mediator for Hypothesis 5, following the pattern of the mediation and moderation results, neither mental illness status, gender, nor the interaction term of the two variables significantly contributed to perceptions of target warmth. Individual values are not summarized here as they are provided for the same relationships examined in Hypothesis 6 results. The index of moderated mediation was non-significant at .001 (standardized index $=.0005), S E=.07,95 \%$ CI $[-.15, .12]$, indicating no significant difference between the non-significant indirect effects through warmth for targets who were women, $\mathrm{B}=-.02, S E=.05, \beta=-.01,95 \% \mathrm{CI}[-.13, .05]$, and men targets, $\mathrm{B}=-.02, \mathrm{SE}=.05, \beta=-.01,95 \% \mathrm{CI}[-.12, .08]$. These results indicate that for the current sample, gender does not demonstrate a significant influence on the indirect effect of mental illness status on ostracism intentions toward target through perception of target warmth. Please refer to Table 8 for full moderated mediational results.

Finally, the results of examining competence as an alternate mediator for Hypothesis 6 follow the pattern of the mediation and moderation results. Neither mental illness status, gender, nor the interaction term of the two variables significantly contributed to perceptions of target competence. Individual values are not summarized here as they are provided for the same relationships examined in Hypothesis 5 results. The index of moderated mediation was non-significant at -.09 (standardized index $=$ $.04), S E=.11,95 \%$ CI $[-.15, .13]$, indicating no significant difference between the nonsignificant indirect effects through competence for targets who were women, B = -.01, $S E$ $=.07, \beta=-.003,95 \% \mathrm{CI}[-.15, .13]$, and men targets, $\mathrm{B}=.08, \mathrm{SE}=.09, \beta=.04,95 \% \mathrm{CI}$ $[-.09, .26]$. These results indicate that for the current sample, gender does not demonstrate 
a significant influence on the effect of mental illness status on desire to work with the target through perception of target competence.

\section{Supplementary Analyses}

To examine the potential influence of mental illness stigmatizing beliefs that were included as a covariate in original and alternate mediator hypothesis testing, I reconducted the mediational and moderated mediational analyses without the covariate included in the model. Exclusion of the mental illness stigmatizing belief variable did not lead to differential outcomes for any of the hypotheses, and no changes in standardized coefficients larger than .03 were observed. The indirect effect of mental illness status on ostracism intentions remained nonsignificant through both competence and warmth (-.02 to .0002 , standardized effect size $=$

-.01 to .001). The indirect effect of mental illness status on desire to work with the target remained nonsignificant through both mediators as well (both indirect effects $=.02$, standardized effect size $=.01)$. The direct effect of mental illness on ostracism intentions remained nonsignificant $(.0002$, standardized effect size $=.0001)$, and the direct effect of mental illness status on desire to work with the target remained significant (-.23, standardized effect size $=$

-.12). Further, all indices of moderated mediation remained nonsignificant (-.01 to .01, standardized indices $=-.005$ to .003$)$. Collectively, these results suggest that while mental illness stigmatizing beliefs did contribute to the models in hypothesis testing, their presence or absence did not lead to statistically different results. 


\section{Chapter 5: Discussion}

The current study utilized an experimental online study to examine how a worker's mental illness status and gender may jointly influence potential coworkers' perceptions of their competence and warmth, and subsequently, how likely potential coworkers are to either ostracize or desire to work with them. In this study, no hypothesized relationships, nor those examining alternate mediators (e.g., target competence instead of target warmth), were supported. Target mental illness status did not predict ostracism intentions indirectly through perceptions of target competence or warmth, nor was desire to work with the target predicted by target mental illness status through perceptions of target warmth or competence. Further, target gender did not interact with target mental illness status to predict either target competence or target warmth. Finally, gender was not a significant boundary condition for the indirect relationships between (a) target mental illness status, target competence, and ostracism intentions; (b) target mental illness status, target warmth, and ostracism intentions; (c) target mental illness status, target warmth, and desire to work with target; or (d) target mental illness status, target competence, and desire to work with target. Interestingly, target mental illness status demonstrated a significant direct effect on desire to work with the target, such that participants endorsed a greater desire to work with new coworkers who did not have a mental illness. Furthermore, both target competence and target warmth were significantly related to desire to work with the target. Finally, contrary to hypotheses and past literature, target warmth, but not target competence, was significantly related to ostracism intentions toward target.

\section{Theoretical Implications}


The current study expands upon workplace stereotype research by exploring perceptions of competence and warmth simultaneously, examining each construct as a separate mechanism toward interpersonal intentions while accounting for the potential effects of the alternate construct. Hence, the current study contributes to the growing body of literature focusing on workplace interpersonal mistreatment of individuals managing mental illness (see Corrigan et al., 2007; Follmer \& Jones, 2017). Unfortunately, indirect effect hypotheses, moderational hypotheses, and moderated mediational hypotheses from the current study were not supported. Potentially due to shortcomings in the experimental design, there were no differences between study conditions in competence and warmth perceptions (see Table 5). There are three potential explanations for the lack of differences between experimental conditions on focal mediators: (a) the experimental conditions lacked distinction due to similarity and the possible presence of confounding variables, (b) participant perceptions of the target were influenced more strongly by the return-to-work scenario than the experimental condition (i.e., mental illness status), and (c) the "dose" of condition manipulation was too light, preventing participants from fully comprehending the identity of the target. Details of these three limitations along with suggestions for remedies in future research are discussed in the Limitations and Future Directions section. Despite these limitations, I identified two interesting findings that further the conversations on workplace mental illness stigma and the impacts of stereotypes on workplace interpersonal intentions.

Contributing to workplace mental illness literature, target mental illness status directly predicted desire to work with the target, such that participants were less desirous of working with a worker with mental illness than a worker returning from a car accident. 
Interestingly, this direct relationship existed exclusive of the influence of competence or warmth perceptions, as hypotheses of indirect relationships were not supported. This finding is in line with Follmer and Jones' (2018) review on workplace mental illness, which found that across the existing literature, reactions to workers with mental illness are generally negative even exclusive of stereotype endorsements.

Two potential alternative mechanisms may be responsible for influencing a person's desire to work with a mentally ill coworker. First, research on reactions to workers with mental illness has identified that others perceive them as dangerous, partly due to the unpredictability inherent in their behaviors (Angermeyer \& Matschinger, 1996; Corrigan et al., 2002). Perceptions of danger can incite an automatic and subconscious fearful emotional reaction, and subsequent desire to avoid the person. This process exhibits a variation on Weiner's (1995) primary appraisal: the response of fear to a person with mental illness directly influences the desire to avoid them without requiring any attributional mediator (Corrigan et al., 2002). Indeed, Corrigan and colleagues (2007) found that when compared to workers with a physical disability, people rated potential workers with mental illness as dangerous, were more afraid of them, and were less likely to include them in job-related activities.

Stereotype research suggests a second potential mechanism for the influence of mental illness status on lower desire to work with a target individual: there may be a moral component to stereotypes. In this case, individuals not only evaluate others on their competence and warmth, but also on their perceived morality. Workers with mental illness have great potential to be the victims of morality judgments, particularly as mental illness is often considered a condition that is illegitimate or the target's own fault 
(Corrigan et al., 2007; Follmer \& Jones, 2018). The manipulation for the current study explained that the target was returning from five weeks of health leave. The inconsistency inherent in the length of leave combined with an asymptomatic target upon return may have increased participants' questions of legitimacy of the condition (Follmer \& Jones, 2018). As a decrease of legitimacy in an employment domain suggests that the worker is not "earning their keep" and may be benefitting from the efforts of others, that worker may be perceived as acting against societal-level expectations of right and wrong, decreasing perceptions of the morality of the target. Previous research has found that a facet of morality (i.e., trustworthiness) is highly desirable in interaction partners (Cottrell et al, 2007). Hence, individuals may be less likely to want to work with coworkers who they perceive as possessing lower morality, due to the inconsistency and lack of trustworthiness potentially associated with the mental illness status in this study. Considering these two potential alternative mechanisms, decisions to socially include or exclude individuals with mental illness may not solely result from competence and warmth stereotype endorsements.

Extending the workplace stereotype literature, for the current sample, the influences of warmth and competence on interpersonal intentions did not follow theoretically based predictions. Participants' ostracism intentions were only predicted by perceptions of target warmth, not competence perceptions, though the BIAS map demonstrates that perceptions of lower competence predict passive harming behaviors, including social exclusion (Cuddy et al., 2007). Furthermore, the desire to work with the target was predicted by both competence and warmth, though according to the BIAS map active facilitation in the form of inclusion into social networks should be the results of 
higher perceptions of target warmth (Cuddy et al., 2007). Interestingly, in the current sample the effect of competence on desire to work with the target appeared larger $(b=$ $.64,95 \%$ CI $[.43, .85])$ than the effect of warmth $(b=.40,95 \%$ CI $[.20, .59])$, though the confidence intervals for the coefficients of both warmth and competence overlap, indicating that the size of their effects may not be significantly different (Myers et al., 2010). Taken together, these findings suggest that for the current sample overall warmth may be a more influential mechanism for predicting workplace interpersonal outcomes than competence, which is a different pattern of results for workplace outcomes than found in the recent literature (see Follmer \& Jones, 2017; Martinez et al., 2016, Masser et al., 2007).

There are two potential explanations for this deviation from expected outcomes. First, expressions of helping and harming behaviors may be altered in the workplace. The BIAS map proposes that perceptions of higher warmth predict active facilitation and perceptions of lower warmth predict active harm (Cuddy et al., 2007). Traditionally, active harm would display as an overt behavior such as harassment. In the workplace context, however, the norms of respect and general enforcement of anti-harassment policies decrease the likelihood of overt harassment as an outcome of lowered warmth perceptions, increasing the likelihood that active harming behaviors in the workplace are enacted as intentional forms of passive harming behaviors (Dipboye \& Halverson, 2004; Follmer \& Jones, 2017; Hebl et al., 2002; Martinez et al., 2016). Hence, in the workplace, lower perceptions of warmth may contribute to ostracism as a socially acceptable form of active harm. Furthermore, keeping workplace norms in mind, the dual impact of competence and warmth on desire to work with a person managing mental illness is no 
longer surprising. In this case, lower desire to work with someone represents both the desire for social distance, a passive response as would be predicted by competence perceptions (Cuddy et al., 2007), and a socially acceptable alternative to harassment, an active response of lower inclusion as would be predicted by warmth perceptions (Cuddy et al., 2007). Hence, perceptions of both competence and warmth may predict the desire to work with a potential coworker.

A second explanation for the unexpected effects of competence and warmth perceptions relate to the facets of performance for different work industries. The relative salience of competence or warmth in a work setting influences which stereotype component will predict behavioral responses (Becker \& Asbrock, 2012). Competence is generally salient in the workplace due to the need for workers to be able to successfully complete their job tasks, lending to its greater effect on behavioral outcomes in the work setting in general. There are some industries, however, where warmth can become more salient (e.g., customer service), because measures of employee performance and organizational success are directly related to customer satisfaction (see Smith et al., 2016). The manipulation in the current study specified that the target was a member of a sales team and the purpose of the meeting was to generate ideas to increase sales from new and existing clients. In this situation, where the warmth and likability of a worker's team member may influence both customer satisfaction and subsequent performance, warmth would become a salient stereotype, predicting interpersonal intentions toward the individual (Becker \& Asbrock, 2012). Thus, this saliency effect might explain why warmth predicted both positive and negative interpersonal intentions in the current study. This is not to say that competence would have no effect on interpersonal intentions. 
Particularly when evaluating strangers, individuals rely on competence perceptions to help interpret the strangers' behaviors and to determine appropriate response behaviors (Richetin et al., 2012). Hence, in this environment, perceptions of both warmth and competence have potential to influence coworkers' opinions and behaviors, though warmth demonstrates an influence over a greater number of outcomes. This finding highlights the importance of assessing industry and job roles as potential boundary conditions for organizational theories.

\section{Practical Implications}

Organizations and practitioners should incorporate into the design of organizational procedures and interventions the knowledge that a person's mental illness status predicts a lowered desire to work with them. Since the mental illness stigma a worker faces is reduced when others become acquainted with the worker, organizations should set practices and policies in place that create climates of civility and offer employees more opportunities to socialize with each other, especially when job roles involve interdependence between employees (Follmer \& Jones, 2018). Supervisors and leaders are especially responsible for reinforcing these values, as their positions of power lend their behaviors and attitudes more weight and are often assumed to reflect the values of the group (Tyler et al., 1996). Indeed, Hamann and colleagues (2016) found that training managers how to support individuals with mental illness was related to reduced stigma and reduced negative attitudes towards workers managing mental illness. Hence, providing managers and supervisors with tools to support workers with mental illness potentially benefits the workers through two paths: by directly providing additional support and indirectly increasing the supportive climate of the organization. 
On a larger scale, the current study reinforces the influence of competence and warmth stereotypes on both positive and negative interpersonal outcomes. It also highlights the relative importance of warmth in predicting ostracism intentions. Since ostracism is a low-intensity behavior that contributes to a lack of interpersonal, informational, and task-oriented support among targets, ostracized workers already managing a stigmatized identity may find themselves without the necessary resources to successfully navigate their work tasks and roles (Robinson et al., 2013). Interventions and policies to increase supportive behaviors and reduce negative attitudes toward workers with stigmatized identities should reduce ostracism intentions toward these workers and increase coworkers' desire to work with them through improved stereotypes. Hence, training managers and supervisors to provide support and promote an accepting climate has potential to improve interpersonal workplace conditions for workers managing mental illness and workers managing other stigmatized identities.

\section{Limitations and Future Directions}

As mentioned previously, no hypothesized relationships in this study were supported, with negligible differences in focal mediators (i.e., competence, warmth) by treatment condition. In this section I expand upon the three potential study limitations that account for these results. First, it is likely that the mental illness manipulation did not create clear conditions. The target was identified as a worker with general mental illness. Previous research has demonstrated that evaluations of and reactions to specific mental illness conditions vary by condition (see Follmer \& Jones, 2017; Sadler et al, 2012). Hence, if participants were imagining a specific mental health condition, it is possible that they responded to different imagined mental illness conditions. Additionally, the 
referent/control condition was a worker who was in a car accident. This choice of operationalization left the condition open to potential confounding variables. For example, the following information was left unclear in the manipulation: (a) whether the car accident was the target's fault, (b) whether the target recovered yet from the car accident, (c) whether the target developed a chronic health condition from the car accident, or (d) whether the target sustained a brain injury in the car accident. Additionally, the current study did not explicitly measure competence and warmth perceptions of multiple social groups including workers with mental illness and compare their means, as is recommended by Fiske and colleagues (2002).

I recommend that future researchers examining this topic follow the procedures of Fiske and colleagues (2002) to compare competence and warmth perceptions for each treatment condition (e.g., workers with mental illness, workers returning from medical leave) in the Stereotype Content Model to support hypothesized placement. Following these procedures, I suggest that researchers seeking to use a return-to-work experimental manipulation select a referent group that does not have fault or health-related associations (e.g., worker returning from a sabbatical or using up expiring paid leave).

Second, the use of a health-related return-to-work scenario for both mental illness status conditions (e.g., participants were evaluating workers who returned from a five week health leave due to either a mental health condition or a car accident) may have caused the effect of the general health leave/return-to-work scenario to become the manipulation that participants responded to, regardless of reason for leave or the gender of the target. Return-to-work studies are utilized in published stigma literature, though they are often confined to conditions of mental or physical conditions (see Corrigan et al., 
2002; Thornthwaite \& Markey, 2017). Indeed, empirical research demonstrates that workers with chronic physical conditions, workers who sustained a brain injury, and workers who were injured on the job all experience negative interpersonal reactions upon return to work (Corrigan et al., 2002; Stergiou-Kita et al., 2017; Thornthwaite \& Markey, 2017). Researchers may wish to retain the return-to-work scenario to adequately convey moderate to severe mental illness. In this case, to ensure that participants respond to treatment conditions of future studies and not solely to return-to-work manipulations, study design should ensure that the reason for taking a leave from work is not equivalent between groups (i.e., only the treatment group should take a health leave). If future researchers are interested in mild to moderate mental illness, they should consider substituting the return-to-work manipulation with another plausible reason for an introduction to a work team (e.g., target was recently hired, switched job roles, changed work locations, or joined a new work team).

Third, it is possible that the "dose" of the manipulation was not strong enough to elicit participant reactions. To prime the mental illness condition, the term used throughout stimulus materials referred to a "mental health condition" as opposed to a "mental illness". This light reference, coupled with the lack of apparent symptoms or specific reference to their condition during a chat-style meeting, might have caused participants to use more readily available information when evaluating targets. If participants paid attention to the content of the meeting, they would have observed that the target was specifically presented as a worker who demonstrated generally average levels of competence and warmth. While participants were required to correctly identify the reason for the target's leave, they did not provide any information of whether that 
reason made an impact on them. Furthermore, best practices for experimental vignette methodology calls for between-participant designs (i.e., where participants only see one condition) to provide extra explanation of the issues and context to make sure participants understand the condition they are in (Aguinis \& Bradley, 2014). Additionally, they call for more immersive techniques to strengthen manipulations. Though I attempted to increase realism of the manipulation by having participants watch a screen recording of a chat meeting, this resulted in stimulus of both mental illness and gender conditions that was limited to words. In addition to the light dose of mental illness condition, the lack of a photo of the target may have weakened the gender priming of this study.

Future iterations of this study should include expanded contextual information in the study introduction, introduce multiple references to mental illness, and utilize audio or visual stimulus materials (e.g., audio or video recording, photos) to strengthen immersion into the manipulation. Additionally, I recommend that future researchers verify the success of their experimental manipulations through two possible techniques: the use of two manipulation checks or a qualitative manipulation check. In either situation, participants should be asked to identify both the reason for leave and the name of the target directly after exposure to research materials. If using two manipulation checks, upon completion of target evaluation, participants should be asked again to correctly identify both the reason for leave and the name of the target. Alternatively, if using a qualitative manipulation check, the manipulation check directly after stimulus should also indicate to what degree the participant felt the target was representative of a person with mental illness, and what mental illness they believed the target managed. If there are adequate resources, the most information would be obtained by combining these 
two techniques by retaining all participants regardless of how they answered the manipulation checks, and through exploring potential response differences according to correctness of manipulation check answer and degree of perceived representation. If there are fewer resources, researchers could retain everyone who passed the first manipulation check and use the qualitative manipulation check addition as supplemental information regarding extent of immersion in stimulus materials.

Another limitation of this research is related to its statistical power. Previous analyses indicated that to detect the expected small effect size, a sample of 400 participants would be needed, yet the final sample totaled 242 participants. Specifically, this study might not have the necessary power to detect moderational and moderatedmediation hypotheses due to a sample size that was smaller and more homogeneous than planned. Though a sample size of 242 can be adequate to detect a mediation, considering the small standardized indirect effect coefficients (.002 to .01) obtained from this study, over 500 participants would be necessary to detect the hypothesized mediational relationships (Fritz \& MacKinnon, 2007). Hence, the current study lacked power to detect any of the hypothesized relationships. Indeed, the power of the current sample to detect the standardized index of moderated mediation $(-.04-.001)$ was less that .34 (Preacher et al., 2007). In addition to its size, the sample obtained through random sampling via Qualtrics demonstrated homogeneous responses for core variables $(\mathrm{SD}=$ .60 to .74 ) leading to potential range restriction and reduction of power (Allen \& Yen, 2001). Future studies should take steps to ensure that proposed sample size is achieved, such as by starting with a larger sample at the first time point, allowing for attrition 
greater than $50 \%$. Additionally, they should ensure to cast a wide net when recruiting study participants to gather a diverse final sample.

\section{Conclusion}

The current study built on existing organizational diversity literature to examine how stereotypes associated with mental illness influenced potential coworkers' desire to work with and intentions to exclude a worker managing mental illness. Though results from the experimental manipulation did not support hypothesized relationships, and no intersectional identities combining mental illness and gender influenced stereotype perceptions, results suggest that people express a lower desire to work with workers managing mental illness, regardless of their perception of the worker's competence or warmth. Additionally, between competence and warmth, though warmth perceptions were positively related to a desire to work with a potential coworker and negatively related to intentions to ostracize them, competence was only positively related to desire to work with them. These findings further the efforts of fellow diversity researchers (see Follmer \& Jones, 2017; Martinez et al., 2016) in extending the BIAS map through identification of workplace contexts and industries as boundary conditions of interpersonal reactions to stereotype perceptions. Furthermore, they remind researchers to be mindful of the potential influence of workplace settings on applications of social behavioral theories. Practically, organizations and practitioners may seek to reduce negative workplace interpersonal effects of mental illness and stigmatized identities through implementing interventions and policies to reduce stigma and create supportive climates for affected workers, providing them with resources both directly and indirectly. 
Tables

Table 1

Logistic Regression and Chi-square Attrition Analyses

\begin{tabular}{lcccc}
\hline Variable & $\beta$ & $p$ & $x^{2}$ & $p$ \\
\hline MHSS & -.07 & .31 & & \\
Age & -.002 & .66 & & \\
Work hours & .02 & .09 & & \\
Education & .01 & .79 & & \\
Income & .07 & .10 & & .40 \\
Gender & & & 2.97 & .65 \\
Race & & & 6.01 & .55 \\
LGBTQ & & & 2.09 & .48 \\
Marriage & & & 4.47 & \\
\hline
\end{tabular}

Note: MHSS = Mental Health Stigma Scale; LGBTQ = Member of LGBTQ community.

$\mathrm{N}_{\mathrm{T} 1}=790 ; \mathrm{N}_{\mathrm{T} 2}=371$.

Table 2

Means, Standard Deviations, Correlations, and Reliability of Focal Constructs

\begin{tabular}{llllllll}
\hline Variable & Mean & SD & MHSS & Comp & Warmth & Ostracism & Desire \\
\hline MHSS & 2.93 & 1.02 & $(.87)$ & & & & \\
Competence & 3.23 & .66 & .07 & $(.84)$ & & & \\
Warmth & 3.48 & .69 & .06 & $.69^{* *}$ & $(.89)$ & & \\
Ostracism & 1.33 & .88 & $.26^{* *}$ & $-.14^{*}$ & $-.24^{* *}$ & $(.97)$ & \\
Desire $^{\mathrm{a}}$ & 3.65 & 1.01 & $-.17^{*}$ & $.61^{* *}$ & $.56^{* *}$ & $-.29^{* *}$ & $(.96)$
\end{tabular}

Note $:$ MHSS $=$ Mental Health Stigma Schedule; Comp = evaluations of target competence; Warmth $=$ evaluations of target warmth; Ostracism $=$ ostracism intentions toward target; Desire $=$ desire to work with target. Values in parentheses represent Cronbach's alpha reliability of corresponding scale.

${ }^{\text {a }}$ Desire to work with measure contained only 3 items and had an unusually high reliability, suggesting potential item overlap. This scale was created for this study and future iterations of validation for this scale will examine both narrowness of this construct and wording changes to reduce construct overlap.

$\mathrm{N}=242 . * p<.05 . * * p<.01$. 
Table 3

Results of Confirmatory Factor Analysis of Focal Constructs

\begin{tabular}{lccccc}
\hline Measure & $x^{2}$ & $d f$ & CFI & RMSEA & SRMR \\
\hline MHSS $^{\mathrm{a} b}$ & $125.57^{* *}$ & 23 & .89 & .14 & .10 \\
Competence & $15.31^{* *}$ & 4 & .98 & .11 & .03 \\
Warmth & $9.62^{* *}$ & 2 & .99 & .13 & .02 \\
Ostracism $^{\mathrm{b}}$ & $85.867^{* *}$ & 35 & .94 & .08 & .03 \\
Desire $^{\mathrm{c}}$ & .001 & 1 & 1 & .00 & .003 \\
\hline
\end{tabular}

Note: MHSS = Mental Health Stigma Scale; Competence = evaluations of target competence;

Warmth $=$ evaluations of target warmth; Ostracism $=$ ostracism intentions toward target; Desire $=$ desire to work with target; $x^{2}=$ chi-square; CFI = Comparative Fit Index; RMSEA = Root Mean Square Error of Approximation; SRMR = Standardized Root Mean Square Residual.

${ }^{a}$ Though the model fit for MHSS indicated below acceptable levels of fit, this scale has been validated and published in the existing literature to measure an overall MHSS construct (Dimoff \& Kelloway, 2016). Additionally, as it was used as a covariate in the current study, I did not alter the number of items or factors.

${ }^{\mathbf{b}}$ MHSS and Ostracism scales were estimated with Satorra-Bentler corrections for maximum likelihood mean-adjusted chi-square due to violations of normality.

${ }^{\mathrm{c}}$ The Desire scale contained only three items. To allow the CFA model to identify and to estimate model fit indices, I fixed factor variance. This measure was created for the current study and initial analyses suggest there may be some substantive overlap/repetition among the stem of the three items in the scale. Future steps for this scale development should take into account the narrow nature of the construct and revise specific wording of items to reduce overlap.

$N=242 . * * p<.01$ 
Table 4

Results of Nested Confirmatory Factor Analysis of Hypothesized Model

\begin{tabular}{lcccccccc}
\hline Model $^{\mathrm{a}}$ & $x^{2}$ & $d f$ & $\Delta x^{2 b}$ & $\Delta d f$ & $\Delta x^{2} / \Delta d f$ & CFI & RMSEA & SRMR \\
\hline One Factor & $3198.34^{* *}$ & 434 & & & & .45 & .16 & .21 \\
Four Factor & $1121.73^{* *}$ & 428 & -2676.19 & 6 & $446.03^{* *}$ & .86 & .08 & .08 \\
Five Factor & $659.13^{* *}$ & 411 & -635.348 & 17 & $37.37^{* *}$ & .95 & .05 & .07
\end{tabular}

Note: $x^{2}=$ chi-square; $d f=$ degrees of freedom; CFI = Comparative Fit Index; RMSEA = Root Mean

Square Error of Approximation; SRMR = Standardized Root Mean Square Residual.

One Factor $=$ all items on one factor; Four Factor $=$ Competence and Warmth on one factor; Five Factor $=$ each variable on its own factor. All chi-square change values reflect comparison to the directly previous model.

${ }^{a}$ All models were estimated with Satorra-Bentler corrections for maximum likelihood mean-adjusted (MLM) chi-square due to violations of normality.

${ }^{\mathrm{b}}$ Model comparisons completed with loglikelihood test chi-square.

$N=242 . * * p<.01$

\section{Table 5}

Mean and Standard Deviation of Focal Mediators and Outcomes by Treatment Condition

\begin{tabular}{lcccl}
\hline Group mean & Competence & Warmth & Ostracism & Desire \\
\hline \multirow{4}{*}{ Mental Illness } & $3.24(.61)$ & $3.49(.64)$ & $1.33(.76)$ & $3.56(1.00)$ \\
Car Accident & $3.21(.71)$ & $3.45(.74)$ & $1.34(1.00)$ & $3.76(1.00)$ \\
\hline \multirow{3}{*}{ Woman } & $3.33(.60)$ & $3.55(.66)$ & $3.66(1.01)$ & $1.36(1.03)$ \\
Man & $3.12(.70)$ & $3.40(.71)$ & $3.64(1.01)$ & $1.31(.70)$ \\
\hline
\end{tabular}

Note: Standard deviation values in parentheses directly following mean values.

$N=242$. 
Table 6

Model Estimates for Indirect Effects

\begin{tabular}{lccccc}
\hline Variables & $\beta$ & $S E$ & $t$ & $p$ & $95 \%$ CI \\
\hline & Ostracism Intentions & & \\
MI $\rightarrow$ Competence $\rightarrow$ Ostracism & & & & & \\
$\quad$ Indirect Effect & .002 & $.02^{\mathrm{a}}$ & & & {$[-.26, .16]$} \\
MI $\rightarrow$ Competence & .03 & .09 & .53 & .60 & {$[-.12, .21]$} \\
Competence $\rightarrow$ Ostracism & .06 & .11 & .68 & .50 & {$[-.15, .30]$} \\
MI $\rightarrow$ Warmth $\rightarrow$ Ostracism & & & & & \\
Indirect Effect & -.01 & $.03^{\mathrm{a}}$ & & & {$[-.10, .04]$} \\
MI $\rightarrow$ Warmth & .04 & .09 & .57 & .57 & {$[-.13, .23]$} \\
Warmth $\rightarrow$ Ostracism & -.26 & .11 & -3.12 & .002 & {$[-.55,-.12]$} \\
Direct Effect & -.03 & .11 & -.46 & .64 & {$[-.26, .16]$} \\
\hline & Desire to Work & with Target & & \\
MI $\rightarrow$ Warmth $\rightarrow$ Desire & & & & & \\
Indirect Effect & .01 & .04 & & & {$[-.05, .10]$} \\
MI $\rightarrow$ Warmth & .04 & $.09^{\mathrm{a}}$ & .57 & .57 & {$[-.13, .23]$} \\
Warmth $\rightarrow$ Desire & .27 & .10 & 3.99 & $<.001$ & {$[.20, .59]$} \\
MI $\rightarrow$ Competence $\rightarrow$ Desire & & & & & {$[-.08, .14]$} \\
Indirect Effect & .01 & .06 & & & {$[-.12, .21]$} \\
MI $\rightarrow$ Competence & .03 & $.09^{\mathrm{a}}$ & .53 & .60 & \\
Competence $\rightarrow$ Desire & .42 & .10 & 6.14 & $<.001$ & {$[.21, .59]$} \\
Direct Effect & -.10 & .10 & -2.10 & .04 & {$[-.41,-.01]$}
\end{tabular}

Note: $95 \% \mathrm{CI}=95 \%$ confidence interval. Beta are standardized values.

${ }^{\text {a }}$ Standard errors for indirect effects are computed using percentile bootstrapping.

$N=242$. 
Table 7

Results of Moderation of Mental Illness on Focal Mediators

\begin{tabular}{lccccc}
\hline Variables & $\beta$ & $S E$ & $t$ & $p$ & $95 \%$ CI \\
\hline Competence & & & & & \\
$\quad$ Mental Illness & .03 & .27 & .99 & .33 & {$[-.26, .79]$} \\
Gender & .16 & 27 & 1.60 & .11 & {$[-.10,97]$} \\
$\quad$ MI x Gender & -.06 & .17 & -.87 & .38 & {$[-.48, .18]$} \\
Warmth & & & & & \\
$\quad$ Mental Illness & .03 & .28 & .23 & .82 & {$[-.49, .63]$} \\
Gender & .10 & .29 & .57 & .57 & {$[-.41, .73]$} \\
$\quad$ MI x Gender & -.005 & .18 & -.07 & .94 & {$[-.36, .34]$} \\
\hline
\end{tabular}

Note: $\mathrm{MI}=$ Mental illness. $95 \% \mathrm{CI}=95 \%$ confidence interval. Gender coded with Man as low condition and Woman as high condition. Beta are standardized values.

$N=242$. 
Table 8

Model Estimates for Conditional Indirect Effects

\begin{tabular}{lccc}
\hline Variables & $\beta$ & bootSE & $95 \% \mathrm{CI}$ \\
\hline \multicolumn{4}{c}{ Ostracism Intentions } \\
MI $\rightarrow$ Competence $\rightarrow$ Ostracism & & & \\
$\quad$ Index of Moderated Mediation & -.006 & .04 & {$[-.04, .08]$} \\
Conditional: Men & .005 & .03 & {$[-.04, .08]$} \\
Conditional: Women & -.0005 & .02 & {$[-.05, .03]$} \\
MI $\rightarrow$ Warmth $\rightarrow$ Ostracism & & & \\
Index of Moderated Mediation & .0005 & .07 & {$[-.15, .12]$} \\
Conditional: Men & -.01 & .05 & {$[-.12, .08]$} \\
Conditional: Women & -.01 & .05 & {$[-.13, .05]$} \\
\hline \multicolumn{2}{c}{ Desire to Work with Target } & \\
MI $\rightarrow$ Warmth $\rightarrow$ Desire & & & \\
Index of Moderated Mediation & -.0005 & .08 & {$[-.16, .15]$} \\
Conditional: Men & .01 & .06 & {$[-.08, .15]$} \\
Conditional: Women & .01 & .05 & {$[-.07, .13]$} \\
MI $\rightarrow$ Competence $\rightarrow$ Desire & & & \\
Index of Moderated Mediation & -.04 & .11 & {$[-.32, .13]$} \\
Conditional: Men & .04 & .09 & {$[-.09, .26]$} \\
Conditional: Women & -.003 & .07 & {$[-.15, .13]$}
\end{tabular}

Note: $\mathrm{MI}=$ Mental illness. $95 \% \mathrm{CI}=95 \%$ confidence interval. Beta are standardized values.

$N=242$. 
Figures

\section{Figure 1}

\section{Hypothesized Conceptual Model}

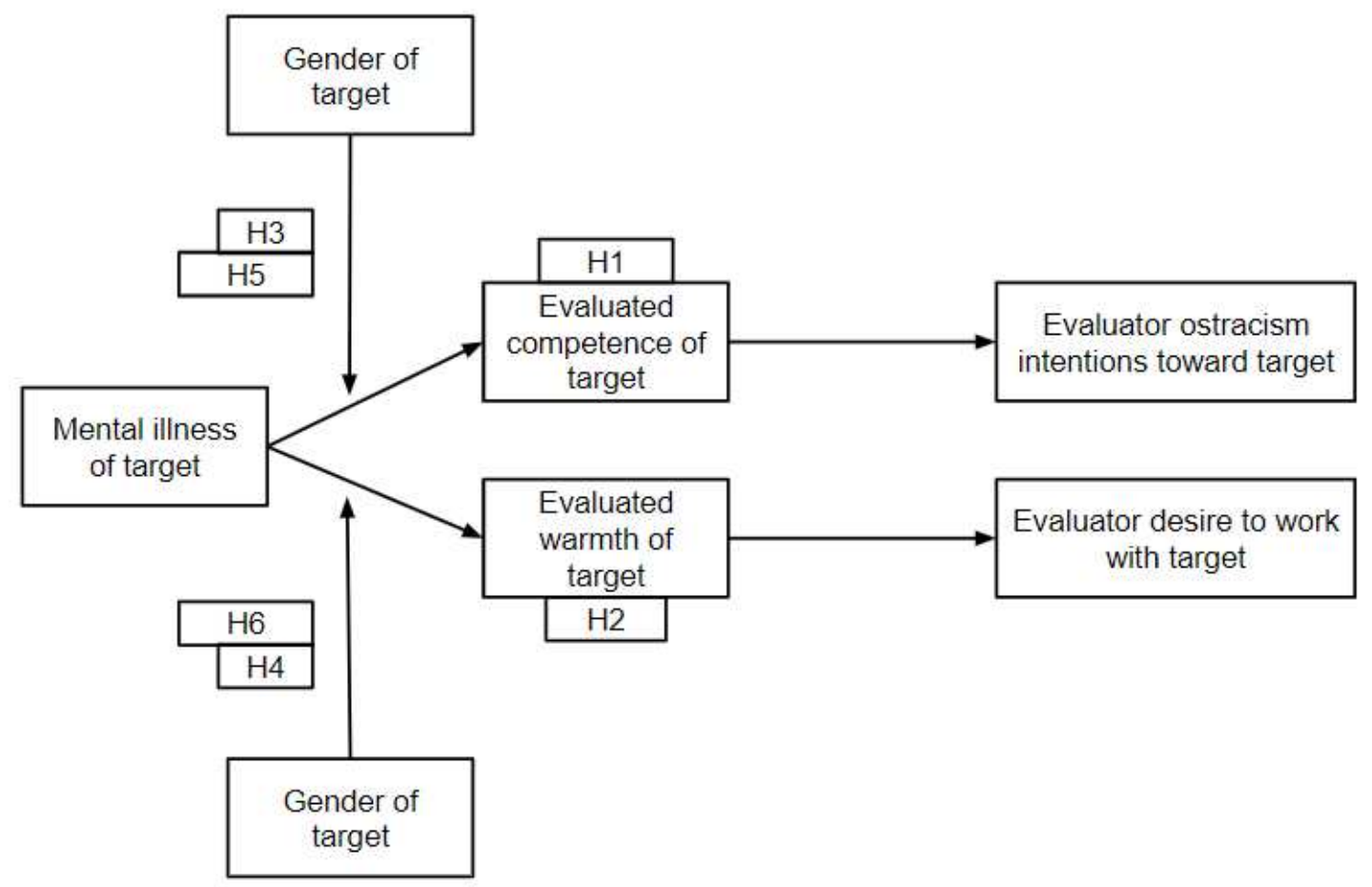




\section{References}

Aguinis, H., Beaty, J. C., Boik, R. J., \& Pierce, C. A. (2005). Effect size and power in assessing moderating effects of categorical variables using multiple regression: A 30-Year review. Journal of Applied Psychology, 90(1), 94-107. https://doi-org /10.1037/0021-9010.90.1.94

Aguinis, A., \& Bradley, K. J. (2014). Best practice recommendations for designing and implementing experimental vignette methodology studies. Organizational Research Methods, 17(4), 351-371. https://doi-org /10.1177/1094428114547952

Allen, M. J., \& Yen, W. M. (2001). Introduction to measurement theory. Waveland Press.

Amodio, D. M., Harmon-Jones, E., Devine, P. G., Curtin, J. J., Hartley, S. L., \& Covert, A. E. (2004). Neural signals for the detection of unintentional race bias. Psychological Science 15(2): 88-93. https://doi-org/10.1111/j.09637214.2004.01502003.x

Angermeyer, M.C., and Matschinger, H. (1996). The effect of violent attacks by schizophrenic persons on the attitude of the public toward the mentally ill. Social Science and Medicine, 43,1721-1728.

Becker, J. C., \& Asbrock, F. (2012). What triggers helping versus harming of ambivalent groups? Effects of the relative salience of warmth versus competence. Journal of Experimental Social Psychology, 48(1), 19-27. https://doi.org/10.1016/j.jesp.2011.06.015 
Berdahl, J. L. (2007). Harassment based on sex: Protecting social status in the context of gender hierarchy. Academy of Management Review, 32(2), 641- 658. https://doi.org//10.5465/amr.2007.24351879

Boas, T. C., Christenson, D. P., \& Glick, D. M. (2020). Recruiting large online samples in the United States and India: Facebook, Mechanical Turk, and Qualtrics. Political Science Research and Methods, 8(2), 232-250. https://doi.org/10.1017/psrm.2018.28

Cascio, W. F. \& Aguinis, H. (2011). Applied psychology in human resource management ( $7^{\text {th }}$ Edition). Pearson.

Chernick, M. R., González-Manteiga, W., Crujeiras, R. M., \& Barrios, E. B. (2011). Bootstrap methods. In M. Lovric (Ed.), International encyclopedia of statistical science (pp. 169-174). Springer

Colella, A., Hebl, M., \& King, E. (2017). One hundred years of discrimination research in the Journal of Applied Psychology: A sobering synopsis. Journal of Applied Psychology, 102(3), 500-513. https://doi.org/10.1037/ap10000084

Corrigan, P. W., Larson, J. E., \& Kuwabara, S. A. (2007). Mental illness stigma and the fundamental components of supported employment. Rehabilitation Psychology, $52,451-457$.

Corrigan, P. W., Rowan, D., Green, A., Lundin, R., River, L., Uphoff-Wasowski, K., White, K., \& Kubiak, M. A. (2002). Challenging two mental illness stigmas: Personal responsibility and dangerousness. Schizophrenia Bulletin, 28, 293-310.

Cotrell, C. A., Neuberg, S. L., \& Li, N. P. (2007). What do people desire in others? A sociofunctional perspective on the importance of different valued characteristics. 
Journal of Personality and Social Psychology, 92, 208-231. https://doi.org $10.1037 / 0022-3514.92 .2 .20$

Crenshaw, K. (1991). Mapping the margins: Intersectionality, identity politics, and violence against women of color. Stanford Law Review, 43(6), 1241-1299. https://www.jstor.org/stable/1229039

Cuddy, A. J. C., Fiske, S. T., \& Glick, P. (2007). The BIAS map: Behaviors from intergroup affect and stereotypes. Journal of Personality and Social Psychology, 92(4), 631- 648. https://doi.org/10.1037/0022-3514.92.4.631

Davidson, H. K., \& Burke, M. J. (2000). Sex discrimination in simulated employment contexts: A meta-analytic investigation. Journal of Vocational Behavior, 56, 225248.

Day, E. N., Edgren, K., \& Eshleman, A. (2007). Measuring stigma toward mental illness: Development and application of the mental illness stigma scale. Journal of Applied Social Psychology, 37(10), 2191-2219. https://doi.org/10.1111/j.15591816.2007.00255.x

Dimoff, J. K., \& Kelloway, E. K. (2016). Resource utilization model: Organizational leaders as resource facilitators. In W. A. Gentry, \& C. Clerkin (Eds.), The role of leadership in occupational stress (pp. 141-160). Emerald Group Publishing. https://doi.org/10.1108/S1479-355520160000014006

Dimoff, J. K., Kelloway, E. K., \& Burnstein, M. D. (2016). Mental health awareness training (MHAT): The development and evaluation of an intervention for workplace leaders. International Journal of Stress Management, 23(2), 167-189. https://doi.org/10.1037/a0039479 
Dipboye, R. L., \& Halverson, S. K. (2004). Subtle (and not so subtle) discrimination in organizations. In R. W. Griffin \& A. O'Leary $\square$ Kelly (Eds.), The dark side of organizational behavior (pp. 131-158). Jossey $\square$ Bass.

Dovidio, J., Major, B., \& Crocker, J. (2000). Stigma: Introduction and overview. In T. Heatherton, R. Kleck, M. Hebl, \& J. Hull (Eds.), The social psychology of stigma (pp. 1-30). Guilford Press.

Eagly, A.H. (1987). Sex differences in social behavior: A social-role interpretation. Lawrence Erlbaum Associates Publishers.

Eagly, A. H., Nater, C., Miller, D. I., Kaufmann, M., \& Sczesny, S. (2019). Gender stereotypes have changed: A cross-temporal meta-analysis of U.S. public opinion polls from 1946 to 2018. American Psychologist, 75(3), 301-315. https://doi.org/10.1037/amp0000494

Eagly, A. H., Wood, W., \& Diekman, A. B. (2000). Social role theory of sex differences and similarities: A current appraisal. In T. Eckes \& H. M. Trautner (Eds.), The developmental social psychology of gender (pp. 123-174). Lawrence Erlbaum Associates Publishers.

Fiske, S. T., Cuddy, A. J. C., Glick, P., \& Xu, J. (2002). A model of (often mixed) stereotype content: Competence and warmth respectively follow from perceived status and competition. Journal of Personality and Social Psychology, 82(6), 878902. https://doi.org /10.1037/0022-3514.82.6.878

Follmer, K. B., \& Jones, K. S. (2017). Stereotype content and social distancing from employees with mental illness: The moderating roles of gender and social 
dominance orientation. Journal of Applied Social Psychology, 47(9), 492-

504. https://doi.org/10.1111/jasp.12455

Follmer, K. B., \& Jones, K. S. (2018). Mental illness in the workplace: An interdisciplinary review and organizational research agenda. Journal of Management, 44(1), 325-351. https://doi.org/10.1177/0149206317741194

Fritz, M. S., \& MacKinnon, D. P. (2007). Required sample size to detect the mediated effect. Psychological Science, 18(3), 233-239.

Goffman, E. (1963). Stigma: Notes on the management of spoiled identity. Prentice-Hall.

Griffin, M. A., \& Clarke, S. (2011). Stress and well-being at work. In S. Zedeck (Ed.), APA Handbooks in Psychology. APA handbook of industrial and organizational psychology, Vol. 3. Maintaining, expanding, and contracting the organization (pp. 359-397). American Psychological Association. https://doi.org/10.1037/12171-010

Griffiths, K., Christensen, H., Jorm, A., Evans, K., \& Groves, C., (2004). Effect of webbased depression literacy and cognitive-behavioural therapy interventions on stigmatising attitudes to depression: Randomised controlled trial. The British Journal of Psychiatry, 185(4), 342-349. https://doi.org/10.1192/bjp.185.4.342

Hamann, J., Mendel, R., Reichhart, T., Rummel-Kluge, C., \& Kissling, W. (2016). A “mental-health-at-the-workplace” educational workshop reduces managers' stigma toward depression. The Journal of Nervous and Mental Disease, 204, 6163. 
Hand, C., \& Tryssenaar, J. (2006). Small business employers' views on hiring individuals with mental illness. Psyciatric Rehabilitation Journal, 29(3), 166-173. https://doi.org/10.2975/29.2006.166.173

Hayes, A. F. (2017). Introduction to mediation, moderation, and conditional process analysis: A regression-based approach ( $2^{\text {nd }}$ Edition.). Guilford Press.

Hebl, M. R., Foster, J. B., Mannix, L. M., \& Dovidio, J. F. (2002). Formal and interpersonal discrimination: A field study of bias toward homosexual applicants. Personality and Social Psychology Bulletin, 28, 815- 825. https://doi.org/10.1177/0146167202289010

Hebl, M., Madera, J. M., \& King, E. (2008). Exclusion, avoidance and social distancing. In K. M. Thomas (Ed.), Diversity resistance in organizations (pp. 127-150). Taylor \& Francis Group.

Heilman, M. E., \& Eagly, A. H. (2008). Gender stereotypes are alive, well, and busy producing workplace discrimination. Industrial and Organizational Psychology, 1(4), 393-398. https://doi.org/10.1111/j.1754-9434.2008.00072.x

Heilman, M. E., Wallen, A. S., Fuchs, D., \& Tamkins, M. M. (2004). Penalties for success: Reactions to women who succeed at male gender-typed tasks. Journal of Applied Psychology, 89(3), 416-427. https://doi.org/10.1037/0021-9010.89.3.416

Hershcovis, S. M. (2011). "Incivility, social undermining, bullying...oh my!": A call to reconcile constructs within workplace aggression research. Journal of Organizational Behavior, 32(3), 499-519. https://doi.org/10.1002/job.689 
Huang, J. L., Curran, P. G., Keeney, J., Poposki, E. M., \& DeShon, R. P. (2012).

Detecting and deterring insufficient effort responding to surveys. Journal of Business and Psychology, 27(1), 99-114.

Ipsos Reid. (2012). "Depression in the Workplace”, July 18-24, [Survey Report] Retrieved from https://www.workplacestrategiesformentalhealth.com/mediacentre

Kroska, A., Harkness, S. K., Brown, R. P., \& Thomas, L. S. (2015). Gender, status, and psychiatric labels. Social Science Research, 54, 68-79. https://doi.org/10.1016/j.ssresearch.2015.06.021

Long, J. S., and Ervin, L. (2000), Using heteroscedasticity-consistent standard errors in the linear regression model. The American Statistician, 54, 217-224.

Lucas, J. W., \& Phelan, J. C. (2019). Influence and social distance consequences across categories of race and mental illness. Society and Mental Health, 9(2), 143-157. https://doi.org/10.1177/2156869318761125

Lyons, B., Martinez, L., Ruggs, E., Hebl, M., Ryan, A. M., O’Brien, K., \& Roebuck, A., (2016). To say or not to say: Different strategies of acknowledging a visible disability. Journal of Management, 44(5), 1980-2007. https://doi.org/10.1177/0149206316638160

Martinez, L. R., White, C. D., Shapiro, J. R., \& Hebl, M. R. (2016). Selection BIAS: Stereotypes and discrimination related to having a history of cancer. Journal of Applied Psychology, 101(1), 122-128. https://doi.org/10.1037/ap10000036

Masser, B., Grass, K., \& Nesic, M. (2007). 'We like you, but we don’t want you'-The impact of pregnancy in the workplace. Sex Roles, 57(9-10), 703-712. 
Moss-Racusin, C. A. (2014). Male backlash: Penalties for men who violate gender stereotypes. In R. J. Burke and D. A. Major (Eds.) Gender in Organizations. Edward Elgar Publishing.

Moss-Racusin, C. A., Phelan, J. E., \& Rudman, L. A. (2010). When men break the gender rules: Status incongruity and backlash against modest men. Psychology of Men \& Masculinity, 11(2), 140-151. https://doi.org/10.1037/a0018093

Muthén, L.K., \& Muthén, B.O. (2017). Mplus User’s Guide. Eighth Edition. Muthén \& Muthén.

Myers, J. L., Well, A. D., \& Lorch, R. F., Jr. (2010). Research design and statistical analysis ( $3^{\text {rd }}$ Edition). Routledge.

National Institute of Mental Health. Any Mental Illness (AMI) Among Adults. (n.d.). Retrieved October 23, 2019.

Noe, R. A. (2020). Employee training and development ( $8^{\text {th }}$ Edition). McGraw Hill Education.

Nunnally, J. C. (1978). Psychometric theory (2nd ed.). McGraw-Hill.

Preacher, C. J., Rucker, D. D., \& Hayes, A. F. (2007). Addressing moderated mediation hypotheses: Theory, methods, and prescriptions. Multivariate Behavioral Research, 42(1), 185-227. https://doi.org/10.1080/00273170701341316

Reilly, E. D., Rackley, K. R., \& Awad, G. H. (2017). Perceptions of male and female STEM aptitude: The moderating effect of benevolent and hostile sexism. Journal of Career Development, 44(2), 159-173. https://doi.org/10.1177/0894845316641514 
Richetin, J., Durante, F., Mari, S., Perugini, M., \& Volpato, C. (2012). Primacy of warmth versus competence: A motivated bias? The Journal of Social Psychology, 152(4), 417-435. https://doi.org/10.1080/00224545.2011.623735

Robinson, S. L., O'Reilly, J., \& Wang, W. (2013). Invisible at work: An integrated model of workplace ostracism. Journal of Management, 39(1), 203-231. https://doi.org/10.1177/0149206312466141

Sadler, M. S., Kaye, K. E., \& Vaughn, A. A. (2015). Competence and warmth stereotypes prompt mental illness stigma through emotions. Journal of Applied Social Psychology, 45(11), 602-612. https://doi.org/10.1111/jasp.12323

Sadler, M. S., Meagor, E. L., \& Kaye, K. E. (2012). Stereotypes of mental disorders differ in competence and warmth. Social Science \& Medicine, 74(6), 915-922. https://doi.org/10.1016/j.socscimed.2011.12.019

Smith, N. A., Martinez, L. R., \& Sabat, I. E. (2016). Weight and gender in service jobs: The importance of warmth in predicting customer satisfaction. Cornell Hospitality Quarterly, 57(3), 314-328. https://doi.org/10.1177/1938965515622564

Stangor, C., Lynch, L., Duan, C., \& Glas, B. (1992). Categorization of individuals on the basis of multiple social features. Journal of Personality and Social Psychology 62(2): 207-18.

Stergiou-Kita, M., Grigorovich, A., Damianakis, T., Le Dorze, G., David, C., Lemsky, C., \& Hebert, D. (2017). The big sell: Managing stigma and workplace discrimination following moderate to severe brain injury. Work, 57, 1-14. https://doi.org/10.3233/WOR-172556. 
Thornthwaite, L., \& Markey, R. (2017). Return to work after workplace injury: Injured workers, insurers and employers. Australian Journal of Social Issues, 52(2), 98115.

Tyler, T. R., Degoey, P., \& Smith, H. J. (1996). Understanding why the justice of group procedures matters: A test of the psychological dynamics of the group-value model. Journal of Personality and Social Psychology, 70, 913-930. https://doi.org/10.1037/0022-3514.70.5.913

Women's Bureau. (2018). Employment and earnings by occupation. U.S. Department of Labor, Women's Bureau. https://www.dol.gov/agencies/wb/data/occupations Wu, L.-Z., Ferris, D. L., Kwan, H. K., Chiang, F., Snape, E., \& Liang, L. H. (2015). Breaking (or making) the silence: How goal interdependence and social skill predict being ostracized. Organizational Behavior and Human Decision Processes, 131, 51-66. https://doi.org/10.1016/j.obhdp.2015.08.001

Yang, L.-Q., \& Caughlin, D. E. (2017). Aggression-preventive supervisor behavior: Implications for workplace climate and employee outcomes. Journal of Occupational Health Psychology, 22(1), 1-18. https://doi.org/10.1037/a0040148

Yang, L.-Q., Spector, P. E., Chang, C.-H. (Daisy), Gallant-Roman, M., \& Powell, J. (2012). Psychosocial precursors and physical consequences of workplace violence towards nurses: A longitudinal examination with naturally occurring groups in hospital settings. International Journal of Nursing Studies, 49(9), 1091-1102. https://doi.org/10.1016/j.ijnurstu.2012.03.006 


\section{Appendix A: Data Collection Measures}

\section{Time 1 Measures - Participant Attitudes}

Attitudes Toward Mental Illness (Griffiths et al., 2004)

Instructions:

Please use the scale below to rate the extent to which you agree with each statement.

$1=$ Strongly disagree, $2=$ Disagree, $3=$ Somewhat disagree, $4=$ Neutral or don't know, $5=$ Somewhat agree, $6=$ Agree, $7=$ Strongly agree

1. People with a mental health problem are unpredictable.

2. I would not vote for a politician if I knew they suffered from a mental health problem.

3. I would not employ someone if I knew they had a mental health problem.

4. People with mental health problems are dangerous.

5. People with mental health problems could snap out of it, if they wanted.

6. If I had a mental health problem, I would not tell anyone.

7. A mental health problem is a sign of personal weakness.

8. Mental health problems are not real medical illnesses.

9. It is best to avoid people with mental health problems so that you don't develop the problem.

\section{Demographic Items}

What is your gender?

Female

Male

Nonbinary/third gender

Prefer to self-describe

What is your age (in years)?

What is your ethnic background? (Please circle one).

Caucasian

African/Caribbean

Middle-Eastern

South Asian

East Asian/Pacific Islander

Latin

Aboriginal 
Mixed background

Prefer not to disclose

What is the highest degree or level of school you have completed? (If you're currently enrolled in school, please indicate the highest degree you have received.)

Less than a high school diploma

High school degree or equivalent (e.g. GED)

Some college, no degree

Associate degree (e.g. AA, AS)

Bachelor's degree (e.g. BA, BS)

Master's degree (e.g. MA, MS, MEd)

Professional degree (e.g. MD, DDS, DVM)

Doctorate (e.g. PhD, EdD)

What is your current employment status?

Employed full time (36 or more hours per week)

Employed part time (up to 35 hours per week)

What is your marital status?

Single (never married)

Married

In a domestic partnership or long-term committed relationship

Widowed

Divorced

Separated

Please select your current household annual income:

Less than $\$ 20,000$

$\$ 20,000$ to $\$ 34,999$

$\$ 35,000$ to $\$ 49,999$

$\$ 50,000$ to $\$ 74,999$

$\$ 75,000$ to $\$ 99,999$

Over $\$ 100,000$

Do you consider yourself a member of the Lesbian, Gay, Bisexual and/or Transgender (LGBT) community?

(Please circle one).

Yes No No, but I identify as an ally. $\quad$ Prefer not to say. 
Have you or a close friend or family member ever suffered from any type of mental illness? (Please circle one).

Yes $\quad$ No

Do you know of at least one fellow colleague who is or has been on work leave due to a mental illness or mental-health related issue? (Please circle one).

Yes $\quad$ No

\section{Time 2 Measures - Target Evaluation}

Competence and Warmth (Fiske et al., 2002)

Instructions:

Please use the scale below to rate how [NAME] showed these attributes.

$1=$ Not at all, 2=Slightly, 3=Moderately, 4=Very, 5=Extremely

[NAME] is...

competent

confident

independent

competitive

intelligent

tolerant

warm

good natured

sincere

Ostracism Intentions (adapted from Wu et al., 2015)

Instructions:

Please use the scale below to indicate how often you would behave in the following ways toward Individual 1 if you worked at the same location.

$1=$ Never, $2=$ Once in a while, $3=$ Sometimes, $4=$ Fairly often, $5=$ Often, $6=$ Constantly, 7

$=$ Always 
1. I would ignore [NAME] at work.

2. I would leave the area when [NAME] entered.

3. I would not respond to [NAME]'s greetings.

4. I would exclude [NAME] from having lunch together with me.

5. I would avoid [NAME] at work.

6. I would not look at [NAME] at work.

7. I would shut [NAME] out of the conversation.

8. I would refuse to talk to [NAME] at work.

9. I would treat [NAME] as if he or she wasn't there.

10. I would not invite or ask [NAME] if he or she wanted anything when I went out for a coffee break.

Desire to Work With (created from adapted items from organizational diversity

literature, for example see Lyons et al., 2016)

Instructions:

Please use the scale below to indicate how much you want to work with [NAME] in the future.

$1=$ Not at all, $2=$ Not really, $3=$ Neutral, $4=$ Somewhat, $5=$ Very much

1. How much would you want to work with [NAME] every day?

2. How much would you want to work on a special project with [NAME]?

3. How much would you want to work in the same department as [NAME]?

\section{Demographic Items}

The same demographic variables will be collected in Time 1 and 2. Please see pages 6971 for Time 1 demographic variables. 


\section{Appendix B: Stimulus Materials}

\section{Introductory Paragraph}

The introductory paragraph will remain the same substantively for all conditions. The only differences will occur between gender conditions: participant name and gendered pronouns will either be male or female.

"Andrew/Ann has been working in the sales department at Gem Corp for 3 years. Last month he/she was placed on leave and has been absent for 5 weeks. He/she has been receiving treatment on a return-to-work plan and is transitioning back to full-time work over the next 3 weeks. Andrew/Ann is about to have his/her first meeting with his/her sales partner since he/she took leave. Since Andrew/Ann has not transitioned to working in the office yet, this meeting will take place remotely. Imagine that you are a new member of Andrew's/Ann's team and are observing the meeting for training purposes. $\mathrm{He} / \mathrm{She}$ has also sent you an email to introduce himself/herself. Please pay attention to the following email and meeting transcript. After you are finished reading the transcript, you will be asked to answer some questions about the meeting."

\section{Email from Target}

The substantive content of the emails will remain consistent throughout all study conditions. The difference will be a single phrase that explains the reason for the worker's leave. This phrase is italicized in the email text and the alternate sentence for mental health condition is listed below the email.

\section{"Greetings,}

Welcome to the team. I've been out on leave for a little over a month due to a car accident, and am doing a bit of catch-up, so this meeting will be a chance for you to get an idea of what your role will be. Let me know if you have questions about the content of the meeting after we're done.

Regards, Andrew/Ann"

Alternate phrase for mental illness condition: I've been out on health leave for a little over a month due to a mental health condition. 


\section{Work Meeting Transcript}

See below a transcript of the chat meeting participants will view. The substantive content will remain identical for all conditions. The only difference for gender conditions is the name of the workers: Jane/Ann or John/Andrew.

JANET: Hi Ann.

ANN: Hi Janet.

JANET: Welcome back!

ANN: Thanks!

JANET: How's it going? How has your health leave been?

ANN: I'm ready to come back to work. Being gone for 5 weeks is really boring.

JANET: Well, everyone missed you.

How are you feeling about coming back to the office?

ANN: I don't know.

I haven't seen or talked to anyone in over a month.

JANET: That makes sense, but I don't think you need to worry too much.

ANN: Yeah, I just have so much to catch up on and I have to take things slowly because of my return to work plan.

JANET: I think you can only do your best and ask for help when you need it while adjusting back to work.

JANET: Have you reviewed the sales reports I sent you while you were on health leave? I'm not too sure how much you missed.

ANN: I'm still catching up since I wasn't allowed to complete any work while on leave. I knew before I left that we weren't on track to meet our quarterly goal, but it seems like we really fell short.

How bad was it?

JANET: Oh, it was bad. We missed our target by $15 \%$.

ANN: Ouch. I'm sorry! 
JANET: It's particularly bad because our team had the lowest sales in the company. But it would have been worse if you hadn't closed a sale right before you left.

JANET: We're under a lot of pressure from the executive team to make sure it doesn't happen again next quarter.

They want us to make up the deficit over the next two quarters on top of meeting our regular sales goals.

ANN: That's a large goal, and sales this time of year are usually a little slower to begin with.

JANET: Well, we're really going to have to hustle.

Like I said in my last email, each team is responsible for submitting sales-generating ideas.

I know you couldn't get emails while you were out on leave for the past few weeks, so we're a bit behind, and it needs to be submitted today.

I've started on the list, but I need you to contribute some ideas too.

ANN: Nothing like cutting it close. Ok, let's start.

JANET: I've got a few ideas ready, so I'll go first.

JANET: First off, I think we should talk to our existing accounts and ask them for client referrals.

We could offer them a discount or small kickback if their referral creates an account and places an order.

ANN: Oh, I have a discount idea too.

We can offer a discount to clients who place orders over a specific amount.

JANET: We should also offer a single-use slightly larger discount to our top $10 \%$ clients. OR we could combine these last two offers so everyone gets a small discount and the top clients get a larger one.

ANN: Moving away from discounts...

This seems like a good opportunity to see how our clients feel about us.

We can ask a few clients from each tier how we're meeting their needs and what we could improve on.

JANET: Thinking internally, I'd like to help the teams get motivated.

I think our staff would appreciate it if supervisors identified top sales teams in each department in an email and personally acknowledged them. 
ANN: And it would be even more motivating if those sales teams were given some kind of reward. Money would be nice, but even a gift certificate could encourage a little extra effort.

JANET: Alright, I think this is a good list. I'll add these items to the one I started while you were gone and submit it.

I need to go so I can submit this list before the deadline.

ANN: Ok. See you soon.

JANET: And remember, don't worry about your first day back. Everyone's looking forward to seeing you again.

ANN: I'll try to remember that.

JANET: Bye.

ANN: Bye. 